\title{
All nurseries are not created equal: large-scale habitat use patterns in two smalltooth sawfish nurseries
}

\author{
Rachel M. Scharer ${ }^{1, *}$, Philip W. Stevens ${ }^{2}$, Colin P. Shea ${ }^{2}$, Gregg R. Poulakis ${ }^{1}$ \\ ${ }^{1}$ Fish and Wildlife Research Institute, Florida Fish and Wildlife Conservation Commission, \\ Charlotte Harbor Field Laboratory, Port Charlotte, Florida 33954, USA
}

${ }^{2}$ Fish and Wildlife Research Institute, Florida Fish and Wildlife Conservation Commission, St. Petersburg, Florida 33701, USA

\begin{abstract}
Smalltooth sawfish Pristis pectinata use southwest Florida nurseries during at least their first 2 to $3 \mathrm{yr}$, and understanding region-specific habitat use patterns is important for effective management. Research occurred in 2 nurseries within the Charlotte Harbor estuarine system: the Caloosahatchee River, a highly human-altered nursery, and a more natural nursery, the Peace River. Between 2010 and 2013, a total of 148 juveniles ranging from 70.8 to $218.7 \mathrm{~cm}$ stretch total length were caught in gill nets, and 133 were acoustically tagged. The probability of encountering a sawfish during sampling was most influenced by season in both nurseries (highest during spring and summer), followed by dissolved oxygen in the Caloosahatchee River, and salinity and temperature in the Peace River. Temperature had lasting, atypical effects on movements when severe cold events occurred during the study. Outside of these disturbances, sawfish used all habitats available to them in both nurseries, but tended to reside in perennial high-use areas called nursery hotspots. Acoustic monitoring showed that juveniles gradually moved between 4 hotspots along a 20 river kilometer stretch of the Caloosahatchee River with seasonal changes in freshwater inflows or sometimes suddenly in response to large flow events. In contrast, sawfish in the Peace River remained associated with one nursery hotspot year-round. Reasons for these inter-nursery variations are attributed to differences in geomorphology and freshwater inflow regimes. This study illustrates that a full understanding of the life history of a species and the development of a conceptual model requires investigation of the species on a broad spatial scale. This consideration is important to avoid overgeneralization of habitat use patterns between nurseries.
\end{abstract}

KEY WORDS: Pristis pectinata $\cdot$ Acoustic monitoring $\cdot$ Habitat use $\cdot$ Freshwater flow $\cdot$ Extreme climate event $\cdot$ Nursery

\section{INTRODUCTION}

Identification of nurseries is one of the most important initial objectives for conservation of endangered species (e.g. Norton et al. 2012). Multiple lines of evidence qualify an area as a nursery, but nurseries can be difficult to define because they often include a variety of habitats (e.g. estuaries, bays, beaches, surf zones, and coral reefs; Branstetter 1990) that contribute young disproportionately to the adult population (Beck et al. 2001, Heupel et al. 2007). To aid this situation, criteria for defining

${ }^{*}$ Corresponding author: rachel.scharer@myfwc.com nursery habitats have been established for various fields of research (e.g. Nagelkerken et al. 2015). For elasmobranchs, nurseries have been defined as areas in which juveniles (1) are more commonly encountered than in other areas, (2) will return to or remain in, and (3) use across multiple years (Heupel et al. 2007). The functions of elasmobranch nurseries (which are still largely unknown, especially for rays) include protection from predators and access to abundant prey (Branstetter 1990, Simpfendorfer \& Milward 1993, Heupel \& Hueter 2002, Heupel et al. 2007).

() The authors 2017. Open Access under Creative Commons by Attribution Licence. Use, distribution and reproduction are unrestricted. Authors and original publication must be credited. 
Among fish nurseries, estuary geomorphology and associated variability of habitat use can result in spatial differences in life-history traits and movement patterns, making it important to apply species-specific life-history models in multiple nurseries rangewide. For example, juvenile common snook Centropomus undecimalis in one Florida estuarine nursery tended to use freshwater tributaries, while in another they used coastal wetland ponds, creeks, and island networks (Stevens et al. 2007). The contrasts in habitat use were attributed to differences in geomorphology and habitat availability between estuaries. Similarly, seasonal prey availability influenced movements of juvenile bull sharks Carcharinhus leucas in Florida's Shark River estuarine nursery (Matich \& Heithaus 2014), but abiotic variables such as salinity have been more influential on the species in the Caloosahatchee River (Heupel \& Simpfendorfer 2008). Understanding how species use available habitats is critical for understanding range-wide ecosystem function and for effective management of economically important and protected species. These considerations are important to avoid overgeneralization of habitat use patterns between nurseries.

The life-history strategies of many elasmobranchs (e.g. slow growth) make them particularly vulnerable to overexploitation (Frisk et al. 2005), which elevates the urgency to reduce anthropogenic threats and delineate critical habitats such as nurseries. The smalltooth sawfish Pristis pectinata is one of 5 sawfish species worldwide (Faria et al. 2013), and one of 3 species which are Critically Endangered according to the IUCN Red List of Threatened Species (Carlson et al. 2013, Kyne et al. 2013, Simpfendorfer 2013). In 2003, the United States (US) distinct population segment of smalltooth sawfish was designated as the first endangered elasmobranch under the US Endangered Species Act (NMFS 2009). Prior to this US Federal Government listing, little research had been conducted on the smalltooth sawfish. Since listing, however, research and monitoring have intensified, and strides have been made toward understanding basic ecology, life history, and habitat use of the species (e.g. Chapman et al. 2011, Poulakis et al. 2011). This information has enabled the US National Oceanic and Atmospheric Administration's National Marine Fisheries Service (NOAA Fisheries) to develop a smalltooth sawfish recovery plan, designate juvenile critical habitat, and publish two 5 yr status reviews (e.g. NMFS 2009, Norton et al. 2012). Specifically, there are 2 juvenile critical habitat areas, both in southwest Florida: the Charlotte Harbor Estuary Unit and the Ten Thousand Islands/Everglades Unit. Understand- ing how smalltooth sawfish use the nurseries in these regions is imperative for ongoing recovery planning (Norton et al. 2012).

The Charlotte Harbor Estuary Unit of juvenile critical habitat is the focus of this study and contains 2 distinct nursery areas for the smalltooth sawfish: one in the northern portion of the estuary associated with the Peace River, and another in the southern portion associated with the Caloosahatchee River (Seitz \& Poulakis 2002, Poulakis et al. 2011). While both rivers have proven to be consistently important nurseries, each is unique. The Caloosahatchee River, where to date most smalltooth sawfish research has been conducted, has been highly altered by the creation of extensive canal systems, and its freshwater flow is regulated through a lock system (Barnes 2005). Management of freshwater flow down the Caloosahatchee River, which historically flowed south as sheet flow toward the Everglades (Fernald \& Purdum 1998), affects abiotic variables such as salinity as well as habitat use by smalltooth sawfish (Simpfendorfer et al. 2011, Poulakis et al. 2013). In contrast, the Peace River is less developed, with more natural shorelines, and has largely unregulated freshwater flow.

The initial research focus on juvenile smalltooth sawfish in the Charlotte Harbor Estuary Unit of juvenile critical habitat was on the Caloosahatchee River because encounter reports from the public were most common in this area (Seitz \& Poulakis 2002, Poulakis et al. 2011), and funding was limited. Little data from the Peace River contributed to these studies. However, based on lessons learned from other species (Stevens et al. 2007, Matich \& Heithaus 2014), it is important to study nurseries with a variety of geomorphologies and habitat types to understand how they are being used so conservation can be maximized. Four nursery hotspots were identified in the Caloosahatchee River with varying importance over different years depending on freshwater flow conditions (Poulakis et al. 2011, 2013). Acoustic data in the river further confirmed use and movement between these 4 hotspots and identified large-scale movements in response to freshwater releases (Poulakis et al. 2013, 2016). Although smalltooth sawfish were relatively sedentary in the long term, movement data showed that they made quick, large-scale (>20 km) movements in response to some freshwater releases. Salinity proved to be a major influence on seasonal sawfish movements, although movements were temporally lagged, and larger juveniles reacted before smaller juveniles (Poulakis et al. 2013). In general, smalltooth sawfish had strong affinities to these Caloosahatchee River nursery hotspots, regardless of 
abiotic conditions, often associating with the static habitat (e.g. red mangrove shorelines) instead of changing environmental conditions or dynamic habitat (e.g. salinity) (Sklar \& Browder 1998). While sampling effort in northern Charlotte Harbor during these initial studies was not equal, catch data identified at least one nursery hotspot in the Peace River.

The objective of this study was to continue juvenile smalltooth sawfish sampling in the Caloosahatchee River and expand sampling into northern Charlotte Harbor, including the Peace River, so comparisons of habitat use and movements could be conducted between these 2 distinct nurseries over the same multiyear study period. By studying these 2 nurseries during the same time period, using the same techniques and allocation of effort, we could compare large-scale, inter-nursery habitat use by the smalltooth sawfish for the first time.

\section{MATERIALS AND METHODS}

The combination of field sampling, tagging, and data analysis that was previously used to study juvenile smalltooth sawfish Pristis pectinata habitat use in the Caloosahatchee River nursery (Poulakis et al. 2011, 2013, 2016) was expanded to include the Peace River nursery for this study. Ensuring that methods were identical during this study allowed us to make direct comparisons between the only 2 nurseries known from the Charlotte Harbor Estuary Unit of juvenile critical habitat. Similarly, sampling in both nurseries over the same time period allowed us to compare sawfish habitat use, including responses to freshwater inflow, under the same regional climatic conditions.

\section{Field sampling and tagging}

Random and directed sampling were conducted in 2 study areas: southern Charlotte Harbor, which includes the Caloosahatchee River (Fig. 1) and northern Charlotte Harbor, which includes the lower Peace and Myakka rivers (Fig. 2). Data were collected from 2010 to 2013 as part of ongoing research on the smalltooth sawfish (Poulakis et al. 2011, 2013, 2016). Random sampling used standardized methods and will be used in the future to detect long-term changes in relative abundance, while directed sampling used a variety of methods, including any leads from encounters provided by the public, to target smalltooth sawfish to obtain information on movements and habitat use.
Random sampling was conducted during the day from February through September (period of highest catch rates; Poulakis et al. 2011) using two $30.5 \mathrm{~m}$ $(100 \mathrm{ft})$ or two $61 \mathrm{~m}(200 \mathrm{ft})$ gill nets with $102 \mathrm{~mm}$ (4 in.) stretch monofilament mesh set perpendicular to shore about $100 \mathrm{~m}$ apart. Mesh size was chosen to standardize with another smalltooth sawfish survey in Everglades National Park. In general, the $61 \mathrm{~m}$ nets were used unless we were sampling a confined space (e.g. a small creek or canal). In 2010, gill nets with $76 \mathrm{~mm}$ (3 in.) stretched monofilament mesh were also used, but due to higher bycatch rates in these nets, use of this mesh size was discontinued. Two random trips per month were conducted in the lower Caloosahatchee River (Fig. 1; 6 sites $\mathrm{mo}^{-1}, 2$ nets site $^{-1}$ ) and in northern Charlotte Harbor (Fig. 2; 8 sites $\mathrm{mo}^{-1}, 2$ nets site $^{-1}$ ). The study areas were divided into $1 \times 1$ cartographic grids ( 1 nautical mile ${ }^{2}$ ), for which the water was $3 \mathrm{~m}$ deep or less. These grids were organized into 2 sections to facilitate sampling logistics and ensure broad coverage of the nurseries. Grids to be sampled during each month were randomly selected from within each section. Each selected grid was then subdivided into microgrids (using a $10 \times 10$ overlay), and sample sites were randomly selected from these microgrids (i.e. microgrids represented sample sites). A random compass direction (north, east, south, west) and spiral direction (clockwise or counter clockwise) were assigned to each sample site a priori in case any original sample sites needed to be moved (e.g. original site was on land, there was a fisher close to the original site when we arrived). All random gill nets were soaked for $1 \mathrm{~h}$ and were always checked when fish of any type were seen in them (e.g. when splashing was observed) or every $0.5 \mathrm{~h}$, whichever came first. Nets were removed from the water when sawfish were captured so our full attention could be focused on work-up procedures.

Directed sampling was also conducted during the day, targeting areas in which sawfish had been recently reported by the public or sites where sawfish were previously caught (Poulakis et al. 2011, 2013, 2016). Directed sampling averaged 4 sampling trips per month, 2 predominantly in the Peace River and 2 in the Caloosahatchee River. Directed sampling generally occurred between February and September, although sampling was also conducted between October and January to determine effects of unusual events (e.g. cold events; see 'Results: Cold events' and 'Discussion: Aperiodic cold events'). Gear for directed sampling was either two $45 \mathrm{~m}$ (150 ft) gill nets or one $183 \mathrm{~m} \mathrm{(600} \mathrm{ft)} \mathrm{gill} \mathrm{net,} \mathrm{both} \mathrm{with} 152 \mathrm{~mm}$ 


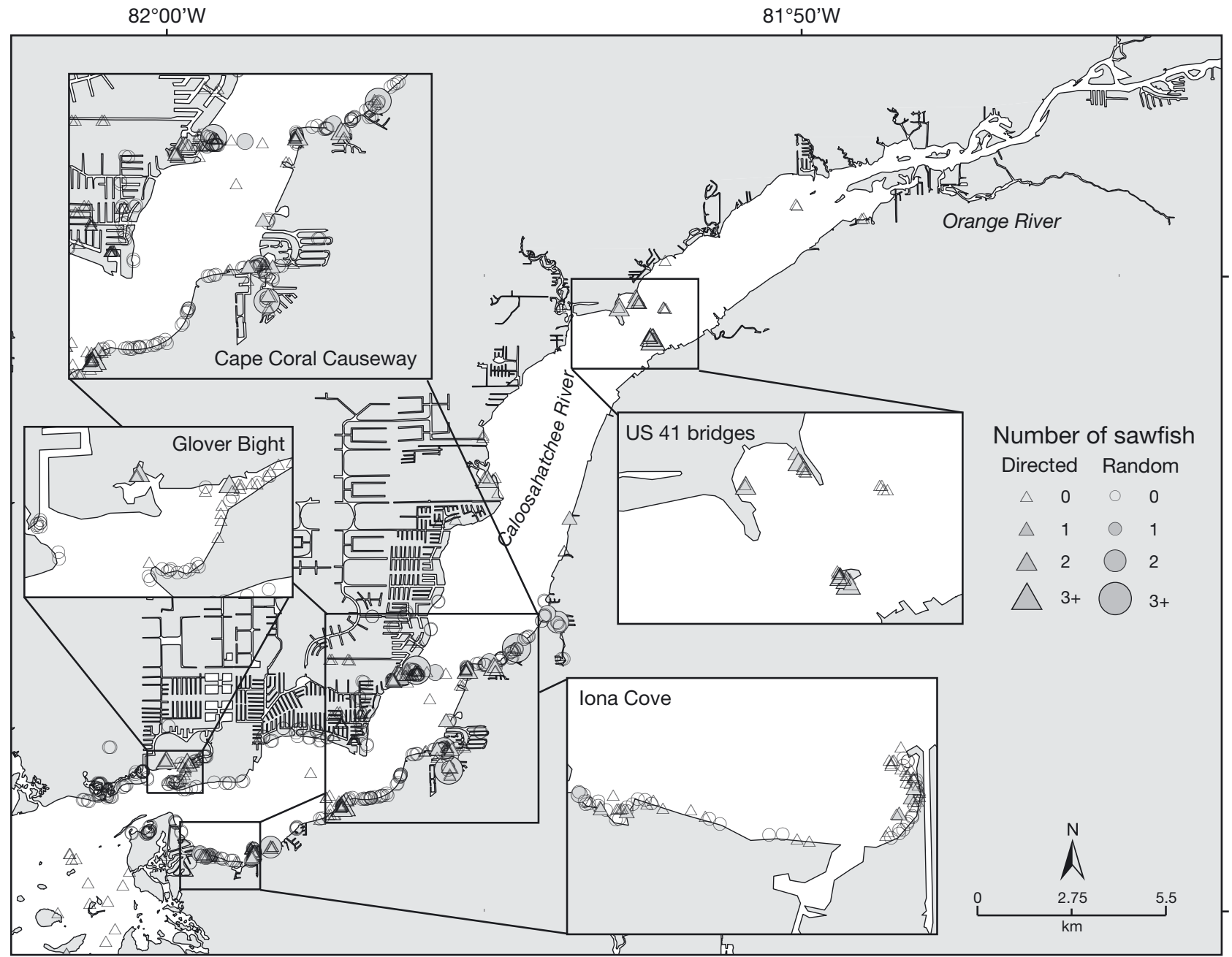

Fig. 1. Sites in the Caloosahatchee River where smalltooth sawfish Pristis pectinata were captured between 2010 and 2013 ; data shown are for directed and random sampling (see 'Field sampling and tagging'). High-use sites (nursery hotspots) where sawfish were captured, tagged, and released are shown in the insets

(6 in) stretch monofilament mesh to minimize bycatch. The $45 \mathrm{~m}$ nets were set perpendicular to shore about $100 \mathrm{~m}$ apart and the $183 \mathrm{~m}$ net began perpendicular to shore, but was usually curved so it eventually became parallel to shore. Directed gill nets were soaked on average for $1 \mathrm{~h}$ and were always checked when fish of any type were seen in them (e.g. when splashing was observed) or every $0.5 \mathrm{~h}$, whichever came first. When water clarity was favorable, we actively searched for sawfish and used gill nets to catch any observed animals. Nets were removed from the water when sawfish were captured so our full attention could be focused on work-up procedures.

Captured smalltooth sawfish were measured (stretch total length [STL], in $\mathrm{mm}$ ), assessed for overall health (e.g. parasites; Bakenhaster et al. 2018, this Theme Section), fin-clipped (free rear tip of second dorsal fin) for DNA and stable-isotope analyses (Poulakis et al. 2017, Feldheim et al. 2017, both this Theme Section), and tagged on the anterior margin of the first dorsal fin with a rototag $(35 \times 9 \mathrm{~mm}$; Dalton ID Systems), at the base of the left side of the first dorsal fin with a passive integrated transponder $(12 \mathrm{~mm}$, $134.2 \mathrm{kHz}$, Super Tag II; Biomark), and on the anterior margin of the second dorsal fin with an acoustic transmitter, as described below.

A variety of environmental and physicochemical variables were recorded at each sampling site using a YSI ${ }^{\circledR}$ hand-held data logger. Specifically, location, time, salinity, water temperature $\left({ }^{\circ} \mathrm{C}\right), \mathrm{pH}$, dissolved oxygen $\left(\mathrm{mg} \mathrm{l}^{-1}\right)$, conductivity, and water depth were recorded. Salinities are reported using the practical salinity scale, which is defined as a pure ratio, and has no dimensions or units. In addition, daily water temperature and freshwater-flow data were obtained 


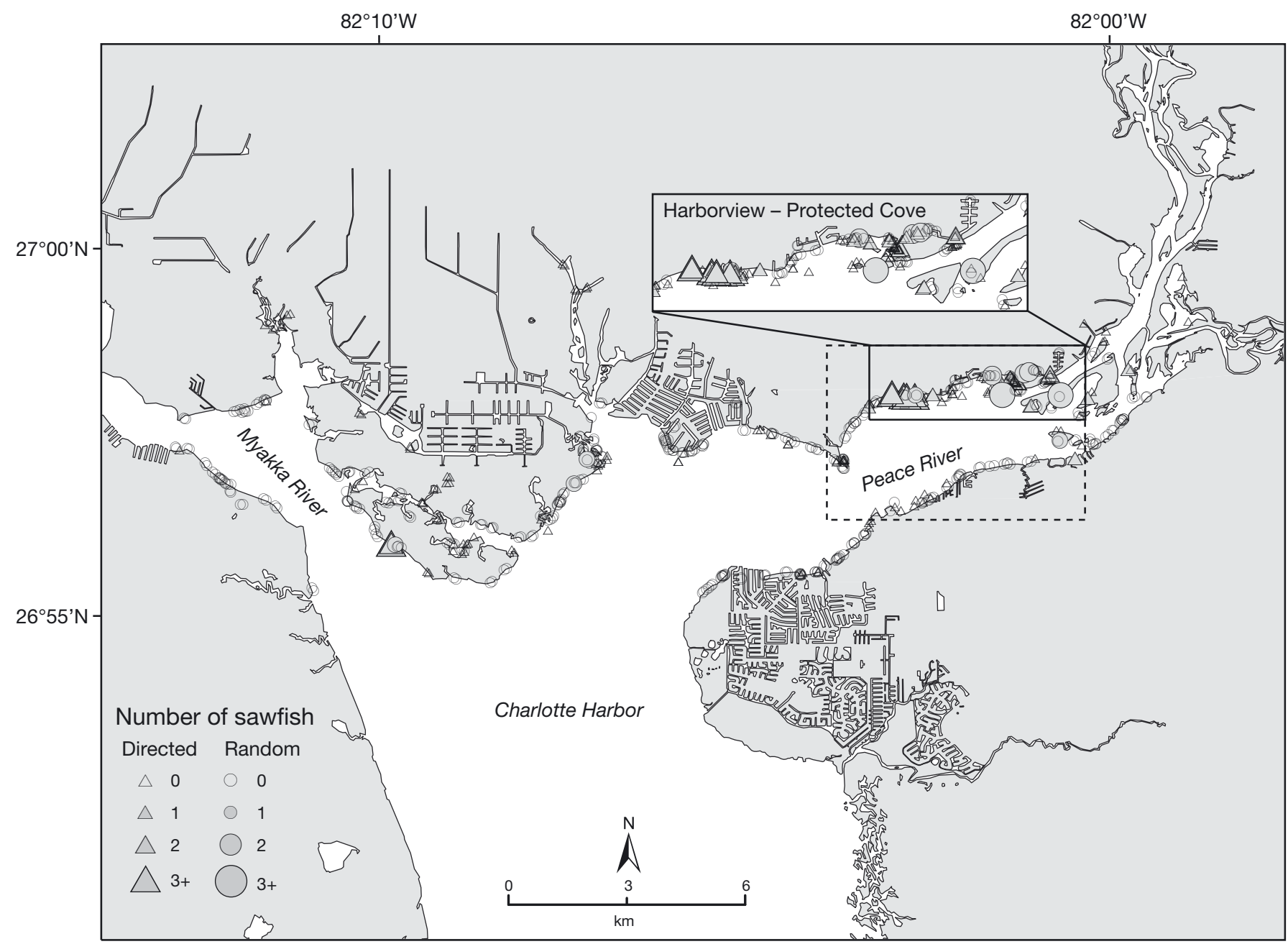

Fig. 2. Sites in northern Charlotte Harbor and the Peace River where smalltooth sawfish Pristis pectinata were captured between 2010 and 2013; data shown are for directed and random sampling (see 'Field sampling and tagging'). Portion of highuse site (nursery hotspot) where sawfish were captured, tagged, and released in the Peace River is shown in the inset; dashed box: the revised hotspot boundary based on Huston et al. (2017)

from fixed stations maintained by the South and Southwest Florida Water Management districts and the US Geological Survey. Observations of shoreline inundation, tidal level, and shoreline and bottom vegetation descriptions (i.e. presence/absence, type, $\%$ coverage) were also recorded.

\section{Acoustic transmitters and acoustic receiver arrays}

Smalltooth sawfish captured during sampling were tagged with a $69 \mathrm{kHz}$ Amirix/Vemco ${ }^{\circledR}$ V9 acoustic transmitter (tag family: V9-2 $\mathrm{H}_{\text {; }}$ frequency-space ID: A69 kHz-1303-ID; 29 mm long, weight in water: 2.9 g). The transmitters were programmed to emit a unique acoustic sequence on a random delay once every 80 to $160 \mathrm{~s}$. The purpose of the delays was to minimize signal collisions when multiple sawfish were simulta- neously within range of an acoustic receiver and to maximize battery life ( $12 \mathrm{mo})$. To comply with our endangered species research permit, acoustic transmitters were attached externally to the second dorsal fin by attaching the transmitter to the flat half of a rototag using a cable tie covered with an epoxy gel. Tags were applied to the thicker, anterior margin of the fin by using a leather punch to make a hole for the projecting half of the rototag and attaching the 2 halves with a tag applicator. These techniques were approved in advance by NOAA Fisheries as outlined in permit numbers 1475 and 15802.

A total of 93 moored, single-frequency omnidirectional VR2W Amirix/Vemco ${ }^{\circledR}$ acoustic receivers were maintained in the Caloosahatchee River (62 receivers) and northern Charlotte Harbor, including the Peace River (31 receivers) to monitor the movements of acoustically tagged smalltooth sawfish (Fig. 3). A 
detailed examination of receiver performance (e.g. code detection efficiency, code rejection coefficients, and noise quotients) in the study area can be found in Simpfendorfer et al. (2008a). Each receiver recorded the date, time, and identity of all tagged sawfish that swam within detection range. The maximum detection radius of the receivers was estimated at $800 \mathrm{~m}$ in the main stem of the Caloosahatchee River (mean = $450 \mathrm{~m}$; Collins et al. 2008). Similar detection ranges were achieved in the non-main-stem habitats, but the acoustic signal did not travel around corners in canals or creeks. Data were downloaded from the receivers, and biofouling was removed from them approximately every other month.

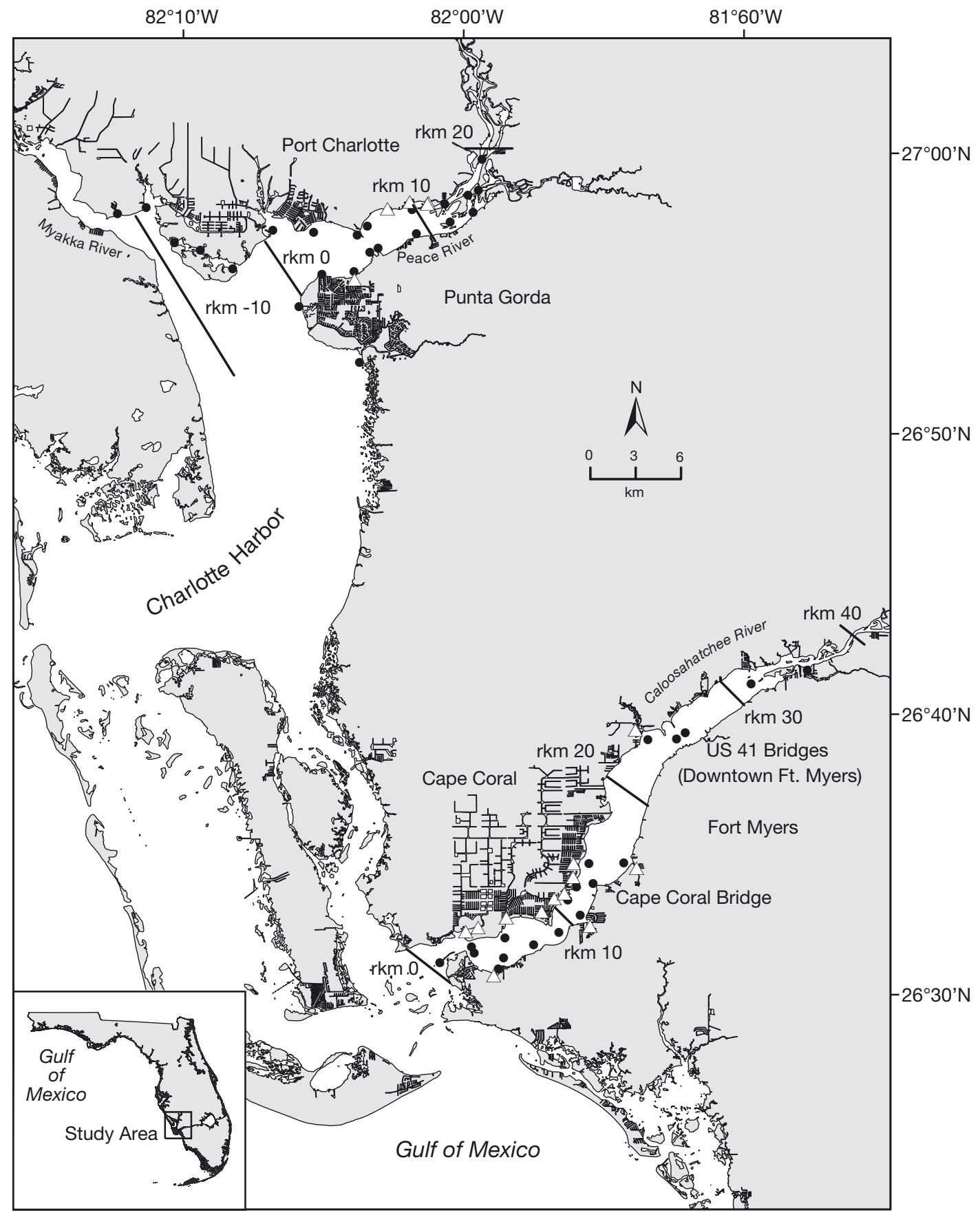

Fig. 3. Northern Charlotte Harbor, Peace River, and Caloosahatchee River study areas and their acoustic receiver arrays used to monitor the movements of acoustically tagged smalltooth sawfish Pristis pectinata (2010 to 2013). Locations of main-stem receivers (dots) and non-main-stem receivers (triangles: creeks, seawall-lined canals) are shown. River kilometer (rkm) refers to the linear distance from the river mouth (at rkm 0) 


\section{Data analysis}

\author{
Catch data
}

Logistic regression was used to determine the influence of abiotic factors on the probability of encountering at least one smalltooth sawfish during sampling (Hosmer \& Lemeshow 2000). As with most ecological studies, the survey methods used in this study likely did not detect sawfish with $100 \%$ efficiency; thus, sawfish encounter probability cannot strictly be interpreted as a probability of occurrence, and quantified relationships between abiotic factors and sawfish encounter probability do not necessarily reflect an affinity for particular abiotic conditions. However, modeling encounter probabilities can help to improve understanding of the conditions under which sawfish are more likely to be observed, and in some cases this may be due to an affinity of sawfish for particular abiotic conditions. Data for the Caloosahatchee and Peace rivers could have been analyzed jointly via inclusion of a site-level categorical covariate and a series of interaction terms, but we opted for analyzing data separately for each nursery. This allowed us to assess the relative influence of various abiotic factors on the probability of encountering sawfish during sampling in each nursery.

Logistic regression models included abiotic predictors for season (winter: December-February, spring: March-May, summer: June-August, and fall: September-November), 4 environmental variables (temperature, dissolved oxygen, salinity, water depth), a quadratic term for each of the 4 environmental variables, and a shore-type categorical variable (i.e. overhanging, altered, and sand/marsh shoreline; hereafter, shore type). The quadratic terms were included to assess the hypothesis that sawfish were more likely to be encountered within a specific range of environmental conditions, rather than a linear relationship. Values for the 4 environmental variables were calculated by averaging surface and bottom values for each sample. The overhanging shore type category was composed mostly of red mangroves Rhizophora mangle and included the non-native Brazilian pepper Schinus terebinthifolius. The altered shore type category included concrete seawalls and rip-rap (i.e. coarse material such as large rocks meant to reduce erosion). The third shore type, sand/marsh, included shorelines that were either unvegetated (e.g. sand beach) or lined with marsh grasses (e.g. Juncus spp.).

For each nursery, a candidate set of 18 logistic regression models was fit, with each model represent- ing a different combination of seasonal, environmental, and shore type predictor variables. To avoid multi-collinearity, predictor variables with Pearson correlation coefficients greater than 0.6 were never included in the same model. To facilitate modelfitting, the 4 continuous environmental predictors were standardized to a mean of 0 and standard deviation (SD) of 1. Following model fitting, the relative plausibility of each candidate model was evaluated using Akaike's information criterion (AIC; Akaike 1973) with a small-sample bias adjustment $\left(\mathrm{AIC}_{\mathrm{c} i}\right.$ Hurvich \& Tsai 1989). To facilitate comparisons among models, Akaike weights were calculated, which range from 0 to 1, and where the best-approximating model had the highest weight (Burnham \& Anderson 2002). Models with Akaike weights that were at least $10 \%$ of the best-approximating model were considered plausible (i.e. a confidence model set), which is similar to Royall's general rule-of-thumb of $1 / 8$ or $12 \%$ for evaluating strength of evidence (Royall 1997). Akaike parameter importance weights were also calculated for each predictor variable as the sum of Akaike weights for candidate models that contained the variable, which enabled comparison of the strength of evidence for each predictor (Burnham \& Anderson 2002). The precision of parameter estimates was assessed by examining $95 \%$ confidence intervals, and parameter estimates with confidence limits that contained zero were considered imprecise. All inferences were based on parameter estimates from the confidence set of models. Lastly, model performance was assessed for the best-approximating model for each study site via calculation of an area under the receiving operator characteristic curve (AUROC) statistic. AUROC values $>0.5$ indicate that a model predicts a given categorical outcome, on average, better than random chance alone. All logistic regression models and the assessments of model performance were conducted in R using the base 'stats' package (R Core Team 2016) and the 'ROCR' package (Sing et al. 2005).

\section{Acoustic data}

The mean position of each smalltooth sawfish within each acoustic receiver array was estimated using a mean-position algorithm (Simpfendorfer et al. 2002, 2008a). To do this, each receiver was assigned a position based on its distance from the river mouth (river kilometer $=0$ ). A geographic information system layer of each river's centerline was extracted from the US Geological Survey National Hydrologic Database (http://nhd.usgs.gov/) and di- 
vided into $0.2 \mathrm{~km}$ (0.1 nautical mile) segments. Each acoustic receiver was assigned a position along the center line of the major river in each array (i.e. Caloosahatchee River or Peace River). Increasing positive distances from each river mouth indicated distances farther upriver. In the northern Charlotte Harbor array, some receivers were placed outside the Peace River and received negative distances relative to its mouth. Increasing negative distances indicated distances farther from the mouth of the Peace River. Once each receiver was assigned a distance, the mean position of a sawfish for a defined time period, $1 \mathrm{~h}$ in this study, was:

$$
\overline{\mathbf{x}}_{\mathrm{km}}=\frac{\Sigma_{i} W_{i} X_{i}}{\Sigma_{i} W_{i}}
$$

where $x_{i}$ is the distance from the acoustic receiver (i) to the river mouth, and $w_{i}$ is the number of valid detections received at each receiver. These mean position estimates formed the basis of all subsequent analyses. For a position estimate to be counted as non-main-stem, a transmitter had to be recorded on a non-main-stem receiver for at least $1 \mathrm{~h}$ (i.e. no mainstem detections occurred). Due to acoustic blind spots in non-main-stem habitats, continuous detections (every 80 to $160 \mathrm{~s}$ ) at a single receiver were not always possible, but as long as no main-stem detections occurred during the hour, we assumed that the individual was located in the non-main-stem habitat. A smalltooth sawfish located between non-mainstem and main-stem receivers would have yielded an estimated position between the receivers and thus would have been placed in the main stem.

We analyzed movement data only for smalltooth sawfish that either retained their acoustic transmitters for at least $2 \mathrm{wk}$, or were recorded at more than one receiver during their monitoring period. Position estimates for individual smalltooth sawfish were used to calculate daily activity space and occurrence by location. Daily activity space was calculated for each individual as the difference between the most upriver and most downriver position estimates for each day. The relationship of maximum daily distance for sawfish in each nursery was found by calculating the maximum daily distances of each sawfish then placing them in $1 \mathrm{~km}$ bins. The number of position estimates was binned into 2 river kilometer sections and plotted to determine high-occurrence portions of the nurseries. The relationship of river kilometer to sawfish position was examined in each study area in more detail by plotting individual sawfish movement tracks with daily mean freshwater inflow data and grouping representative graphs into similar response patterns. The vast majority of acoustic data were collected during the January 2010 to December 2013 study period; however, data from 2 individuals that were tagged in late 2009 and 3 individuals that were monitored into early 2014 were included so their entire monitoring periods could be analyzed. The relationship of salinity to sawfish position was examined in each nursery (1) by plotting the mean daily location of all sawfish that carried tags during the study period and (2) by regressing sawfish location data with salinity using $0,3,7,14,30,60,90$, and $120 \mathrm{~d}$ lags. The regression analysis was conducted separately for 2 time periods (1 Apr 2010 to 31 Dec 2011 and 1 Apr 2012 to 31 Dec 2013) to enable evaluation of the effects of 2 cold events, one in January 2010 that broadly affected the region and altered behavior of many species sensitive to cold (Poulakis et al. 2011, Stevens et al. 2016) and another in December 2010 that had similar effects on fish behavior but was less severe. Mean daily water temperature in the Caloosahatchee (taken at river kilometer 11) and Peace (taken at river kilometer 15) rivers was plotted from 2009 to 2013 to visualize the normal seasonal pattern and the cold events. Similarly, mean daily freshwater flow in the Caloosahatchee (taken at river kilometer 40) and Peace (taken at river kilometer 15) rivers was plotted from 2009 to 2013 to compare and contrast the freshwater flow patterns for the 2 nurseries. Water temperature and freshwater-flow data were obtained from the South and Southwest Florida Water Management districts and the US Geological Survey.

\section{RESULTS}

\section{Spatiotemporal distribution and abiotic affinities}

Between 2010 and 2013, 148 juvenile smalltooth sawfish Pristis pectinata were captured (83 in the Caloosahatchee River nursery, 65 in the Peace River nursery), including 13 recaptures. Although the entire southern Charlotte Harbor region was sampled, the majority (98\%) of the sawfish caught there were in the Caloosahatchee River. Similarly, while the entire northern Charlotte Harbor region was sampled, the majority $(91 \%)$ of the sawfish caught were in the Peace River; therefore, northern Charlotte Harbor data will be referred to as originating in the Peace River. Stretch total lengths ranged from 70.8 to $218.7 \mathrm{~cm}$; all male sawfish were immature based on clasper morphology and lack of calcification, and females were also immature based on known growth rates (Scharer 
et al. 2012). The mean daily activity space for juvenile smalltooth sawfish was $0.9 \mathrm{~km}$ in the Caloosahatchee River and $1.2 \mathrm{~km}$ in the Peace River.

Over the course of the study, at least one sawfish was encountered in 52 of 656 samples $(\sim 8 \%)$ in the Caloosahatchee River and 38 of 635 samples ( 6\%) in the Peace River during random and directed sampling. The confidence sets of Caloosahatchee River and Peace River logistic regression models contained 3 and 4 models, respectively, and both sets indicated support for seasonal and environmental variables as important factors influencing the probability of encountering sawfish during sampling (Tables 1 \& 2). Based on AIC weights, the best-approximating Caloosahatchee River model was 1.98 times more plausible than the next best-approximating model, whereas the best-approximating Peace River model was 4.52 times more plausible than the second best-approximating model. The AUROC statistic for the best-approximating Caloosahatchee River model was 0.69 and the AUROC statistic for the best-approximating Peace River model was 0.75 , indicating that both models predicted the observed data reasonably well.

Parameter estimates from the confidence set of Caloosahatchee River logistic regression models and parameter importance weights based on the candi-

Table 1. Parameter estimates, standard errors (SE), 95\% confidence intervals (lower $=$ LCL and upper $=$ UCL), and odds ratios (OR) from the confidence set of logistic regression models relating smalltooth sawfish Pristis pectinata encounter probabilities to seasonal, environmental, and shore type predictors in the Caloosahatchee River. DO: dissolved oxygen; $\mathrm{DO}^{2}$ : quadratic term that represents a non-linear relationship

\begin{tabular}{|lccrrr|}
\hline Parameter & Estimate & SE & LCL & UCL & OR \\
\hline Best-approximating model & & & & \\
Intercept & -3.068 & 0.300 & -3.705 & -2.523 & \\
Summer & 1.238 & 0.361 & 0.551 & 1.978 & 3.448 \\
Winter & 0.074 & 0.545 & -1.093 & 1.090 & 1.077 \\
Fall & -0.164 & 0.662 & -1.668 & 1.020 & 0.848 \\
DO & 0.394 & 0.146 & 0.106 & 0.680 & 1.482 \\
Second best-approximating model & & & \\
Intercept & -3.032 & 0.302 & -3.673 & -2.481 & \\
Summer & 1.280 & 0.363 & 0.588 & 2.021 & 3.596 \\
Winter & 0.056 & 0.546 & -1.112 & 1.073 & 1.058 \\
Fall & -0.139 & 0.662 & -1.642 & 1.044 & 0.870 \\
DO & 0.468 & 0.179 & 0.132 & 0.838 & 1.596 \\
DO & -0.065 & 0.082 & -0.249 & 0.085 & 0.937 \\
Third best-approximating model & & & \\
Intercept & -3.089 & 0.322 & -3.774 & -2.506 & \\
Summer & 1.457 & 0.466 & 0.577 & 2.414 & 4.292 \\
Winter & -0.345 & 0.628 & -1.658 & 0.839 & 0.708 \\
Fall & -0.061 & 0.694 & -1.608 & 1.202 & 0.941 \\
Temperature & -0.415 & 0.241 & -0.885 & 0.066 & 0.660 \\
\hline
\end{tabular}

date set of models indicated that the probability of encountering a sawfish was most strongly influenced by seasonal effects and dissolved oxygen (Tables 1 \& 3). Sawfish were most commonly encountered during summer relative to spring, fall, and winter, and the odds ratio indicated that sawfish were 3.45 times more likely to be encountered in the Caloosahatchee River during summer than spring. Sawfish encounter probability was also strongly and positively related to dissolved oxygen, with an odds ratio indicating that for every $1 \mathrm{SD}$ (1.83 $\left.\mathrm{mg} \mathrm{l}^{-1}\right)$ increase in dissolved oxygen, sawfish were 1.48 times more likely to be encountered during sampling. Parameter estimates for the remaining predictor variables were considered imprecise as their $95 \%$ confidence intervals contained zero.

Parameter estimates from the confidence set of Peace River logistic regression models and parameter importance weights based on the candidate set of models indicated that the probability of encountering a sawfish was most strongly influenced by seasonal

Table 2. Parameter estimates, standard errors (SE), 95\% confidence intervals (lower $=\mathrm{LCL}$ and upper $=\mathrm{UCL}$ ), and odds ratios $(\mathrm{OR})$ from the confidence set of logistic regression models relating smalltooth sawfish Pristis pectinata encounter probabilities to seasonal, environmental, and shore type predictors in the Peace River. Salinity ${ }^{2}$ and Temperature $^{2}$ : quadratic terms that represent non-linear relationships

\begin{tabular}{|lrrrrl|}
\hline Parameter & Estimate & SE & LCL & UCL & OR \\
\hline Best-approximating model & & & & \\
Intercept & -1.538 & 0.297 & -2.148 & -0.980 & \\
Summer & -0.838 & 0.414 & -1.671 & -0.040 & 0.432 \\
Winter & -17.479 & 1102.924 & -353.063 & 34.721 & 0.000 \\
Fall & -1.598 & 0.625 & -2.951 & -0.447 & 0.202 \\
Salinity & -0.701 & 0.261 & -1.242 & -0.210 & 0.496 \\
Salinity & -0.623 & 0.236 & -1.113 & -0.183 & 0.536 \\
Second best-approximating model & & & \\
Intercept & -2.006 & 0.244 & -2.512 & -1.552 & \\
Summer & -1.433 & 0.510 & -2.443 & -0.432 & 0.239 \\
Winter & -16.583 & 1108.516 & -353.652 & 35.921 & 0.000 \\
Fall & -1.591 & 0.604 & -2.910 & -0.489 & 0.204 \\
Temperature & 0.802 & 0.313 & 0.209 & 1.440 & 2.229 \\
Third best-approximating model & & & \\
Intercept & -1.862 & 0.264 & -2.408 & -1.369 & \\
Summer & -1.221 & 0.520 & -2.260 & -0.211 & 0.295 \\
Winter & -16.258 & 1066.766 & -340.704 & 34.255 & 0.000 \\
Fall & -1.599 & 0.603 & -2.916 & -0.499 & 0.202 \\
Temperature & 0.810 & 0.356 & 0.136 & 1.557 & 2.248 \\
Temperature & -0.366 & 0.300 & -1.036 & 0.154 & 0.693 \\
Fourth best-approximating model & & & \\
Intercept & -2.429 & 0.258 & -2.974 & -1.956 & \\
Summer & -0.277 & 0.372 & -1.023 & 0.448 & 0.758 \\
Winter & -17.349 & 1117.858 & -357.208 & 35.607 & 0.000 \\
Fall & -0.876 & 0.564 & -2.134 & 0.136 & 0.417 \\
Depth & -0.519 & 0.231 & -1.002 & -0.097 & 0.595 \\
\hline
\end{tabular}


Table 3. Importance weights $(w)$ and the number of candidates in the Caloosahatchee River and Peace River logistic regression models (n) in which each parameter was included. Importance weights for quadratic and linear environmental predictors have been combined

\begin{tabular}{|lrl|}
\hline Parameter & $W$ & $\mathrm{n}$ \\
\hline Caloosahatchee River & & \\
Season & 0.98 & 9 \\
Dissolved oxygen & 0.79 & 4 \\
Temperature & 0.11 & 4 \\
Salinity & 0.07 & 4 \\
Depth & 0.02 & 4 \\
Shore type & 0.01 & 2 \\
Peace River & & \\
Season & 1.00 & 9 \\
Salinity & 0.61 & 4 \\
Temperature & 0.24 & 4 \\
Depth & 0.10 & 4 \\
Dissolved oxygen & 0.04 & 4 \\
Shore type & $<0.01$ & 2 \\
\hline
\end{tabular}

effects, salinity, and temperature (Tables 2 \& 3). Sawfish were most likely to be encountered during spring followed by summer, fall, and winter. We note that the exceptionally strong negative effect (and large standard error) of winter resulted from quasi-complete separation, as sawfish were never captured during winter in this nursery. Odds ratios indicated that sawfish were 2.29 times more likely to be encountered for every $1 \mathrm{SD}\left(4.27^{\circ} \mathrm{C}\right)$ increase in temperature. Sawfish encounter probability was also positively related to salinity; however, a strong quadratic effect resulted in a gradual decline in encounter probability when salinity levels exceeded approximately 12. Parameter estimates for the remaining predictors were considered imprecise as their 95\% confidence intervals contained zero.

The 3 shoreline habitat variables (i.e. overhanging, altered, and sand/marsh) were not significant in any of the logistic regression models. In general, smalltooth sawfish were caught near a variety of shore types in both nurseries, including natural shorelines with red mangroves and marsh grasses as well as altered shorelines with seawalls and rip-rap.

\section{Movements}

In total, 133 acoustically tagged juvenile smalltooth sawfish were monitored with acoustic receivers between 2010 and 2013 in the Caloosahatchee River $(\mathrm{n}=76$ total, 47 age 0,29 age $1+)$ and Peace River $(\mathrm{n}=$ 57 total, 49 age 0,8 age 1+). All individuals from the Peace River and most (91\%) from the Caloosahatchee River met the criteria for inclusion in the analysis. The mean $( \pm \mathrm{SE})$ number of days smalltooth sawfish were monitored was $121 \pm 7.9 \mathrm{~d}$ in the Caloosahatchee River and $128 \pm 10.9 \mathrm{~d}$ in the Peace River. About $94 \%$ of the individuals in the Caloosahatchee River and $86 \%$ in the Peace River used nonmain-stem habitats during their monitoring periods. Total non-main-stem activity was $29.1 \pm 3.8 \%$ for the Caloosahatchee River and $11.7 \pm 1.9 \%$ in the Peace River. In the Caloosahatchee River, 35 sawfish (51\%) spent more than $10 \%$ of their time in non-main-stem habitats, and 16 sawfish (23\%) spent more than $50 \%$ of their time there. In the Peace River, 24 sawfish $(42 \%)$ spent more than $10 \%$ of their time in nonmain-stem habitats, and one spent more than $50 \%$ of its time there. In general, non-main-stem activity occurred in habitats that had some red mangrove shoreline ( $50 \%$ or more of the shoreline) rather than in canals that did not have any mangroves (activity in non-main-stem habitats with red mangroves was $24.8 \pm 3.8 \%$ in the Caloosahatchee River and $6.6 \pm$ $1.2 \%$ in the Peace River).

Maximum daily movements and the number of high-use areas (i.e. nursery hotspots) were greater for sawfish in the Caloosahatchee River than in the Peace River. Maximum daily distances traveled in the Caloosahatchee River included longer movements between 10 and 15 river kilometers, whereas maximum daily distances traveled by sawfish in the Peace River were less than 10 river kilometers (Fig. 4). The number of hourly detections in the Caloosahatchee River was greatest between river kilometers 10 and 14 (Cape Coral Causeway hotspot) followed by river kilometers 24 to 26 (US Highway 41 bridges hotspot) (Fig. 5A). Fewer sawfish were caught at the Iona Cove (river kilometer 5) and Glover Bight (river kilometer 3) hotspots between 2010 and 2013 than between 2005 and 2009 (Poulakis et al. 2011), but sawfish caught and acoustically tagged elsewhere were regularly detected in these perennial nursery hotspots. The number of hourly detections in northern Charlotte Harbor was greatest in the Peace River between river kilometers 6 and 12; the portion of the nursery between river kilometers 8 and 10 had more than twice as many hourly detections as the 2 river kilometers sections above and below it, indicating that sawfish from multiple cohorts remained in this small section of the river for much of their monitoring periods (Fig. 5B). This is a portion of the Peace River that includes the only nursery hotspot identified in the river (Harborview-Protected Cove) during almost a decade of research (2005 to 2013). 
Fig. 4. Frequency of maximum daily distances travelled by smalltooth sawfish Pristis pectinata in the Caloosahatchee River (black bars) and Peace River (gray bars) on a logarithmic scale. Maximum daily distances exceeded $9 \mathrm{~km}$ only in the Caloosahatchee River

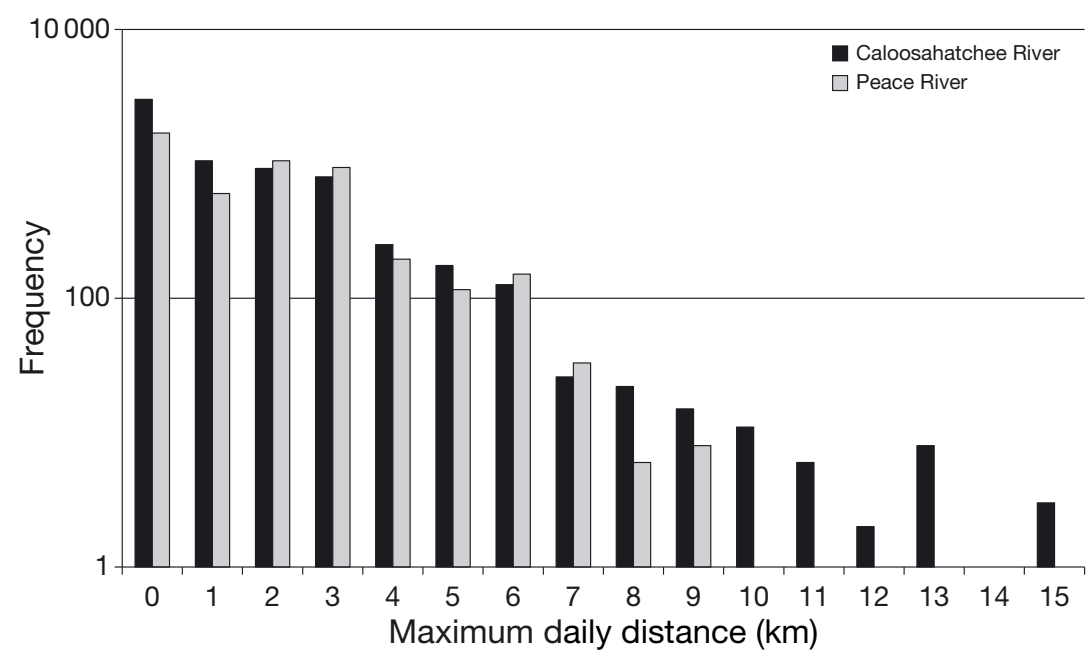

Sawfish were present in both nurseries under a wide range of freshwater inflow and corresponding salinity conditions. Sawfish often responded to changing conditions in the Caloosahatchee River by moving up or down the river (Fig. 6A,B). In general, due to the artificial flow management regime in the Caloosahatchee River, regular freshwater discharges of $\sim 50 \mathrm{~m}^{3} \mathrm{~s}^{-1}$ occurred during the dry season (November to May) to achieve target levels of Lake Okeechobee
(Figs. 6A,B \& 7C). These pulsed freshwater releases coincided with short-term ( 1 to $14 \mathrm{~d}$ ) downriver, then upriver relocations of sawfish that spanned 4 to 16 river kilometers and lasted about 3 mo (Fig. 6B). Sawfish that were tagged in the lower river $(<$ river kilometer 12) tended to stay in the lower river when there were similarly high freshwater discharges (Fig. 6B). In addition, 2 individuals were tagged outside of the Caloosahatchee River, and each made a
Fig. 5. Hourly presence of smalltooth sawfish Pristis pectinata by location (river kilometer, rkm) in the (A) Caloosahatchee River and (B) Peace River nurseries from 2010 to 2013 (rkm $0=$ mouth of the rivers). Increasing positive distances from each river mouth indicated distances farther upriver. In the northern Charlotte Harbor array, some receivers were placed outside the Peace River and received negative distances relative to the river mouth (see Fig. 3). Areas of the Caloosahatchee River at rkm 11 (Cape Coral Causeway) and 25 (US Highway 41 bridges) represent nursery hotspots based on acoustic data and catch data (see Fig. 1). In northern Charlotte Harbor, hourly detections were greatest in the Peace River between river kilometer 6 and 12. This portion of the Peace River represents the only hotspot in this nursery and is based on acoustic data and catch data (HarborviewProtected Cove nursery hotspot; see Fig. 2). In both rivers, these nursery hotspots were consistently used by sawfish between 2005 and 2014 (Poulakis et al. 2011, 2013, 2016, Huston et al. 2017). ND = no data (i.e. no receivers in that portion of the river, see Fig. 3)

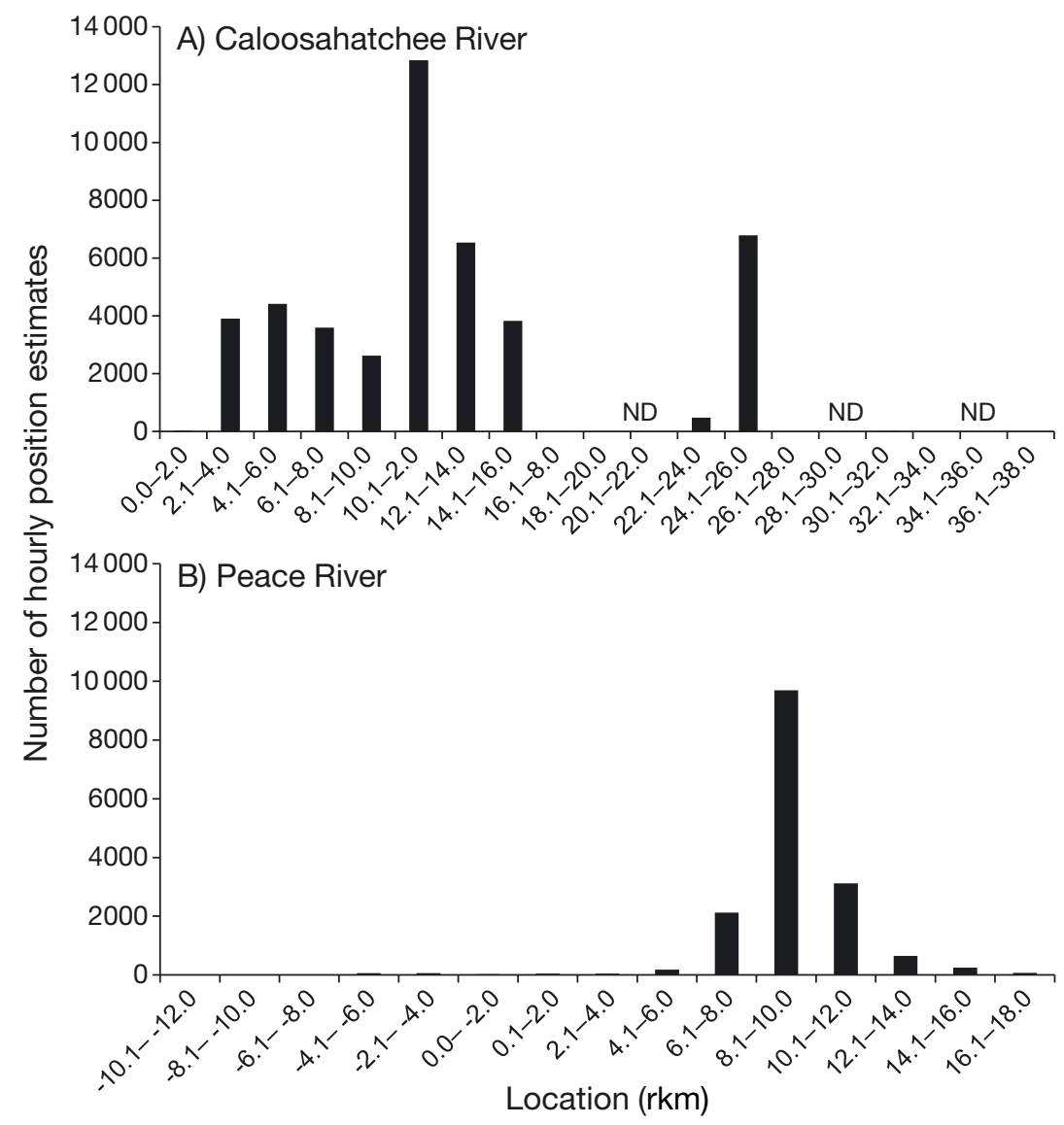



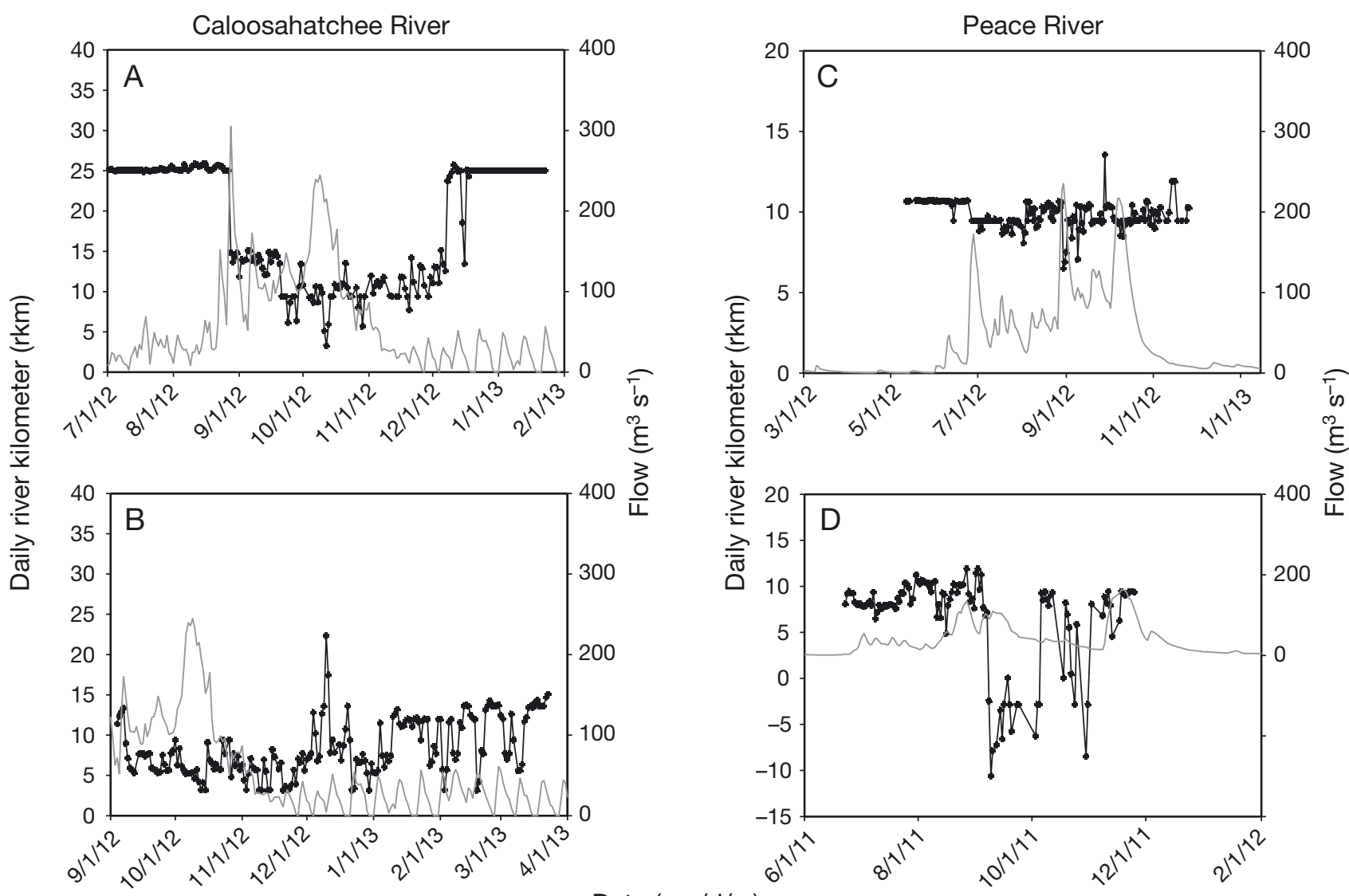

Date $(\mathrm{mo} / \mathrm{d} / \mathrm{yr})$

Fig. 6. Examples of smalltooth sawfish Pristis pectinata movement patterns in both nurseries by date. Solid gray lines: freshwater flow; black lines: movement patterns of individuals. (A,B) Caloosahatchee River: (A) $102.0 \mathrm{~cm}$ stretch total length (STL) sawfish that was tagged upriver and exhibited a response to freshwater inflow by moving downriver and back upriver when flows decreased and (B) $135.6 \mathrm{~cm}$ STL sawfish that was tagged downriver and remained downriver without making any major relocations along the entire length of the river during high freshwater flows. Note the pulsed, dry season, fresh water releases $\sim 50 \mathrm{~m}^{3} \mathrm{~s}^{-1}$ during the latter portions of both time periods. (C,D) Peace River: (C) $77.0 \mathrm{~cm}$ STL sawfish that remained associated with the Harborview-Protected Cove hotspot ( river kilometer [rkm] 10) during a variety of freshwater inflow conditions and (D) $123.0 \mathrm{~cm}$ STL sawfish that exhibited an unusual response to freshwater inflow by moving downriver and back upriver when flows decreased. Movement pattern in D has been observed more often in the Caloosahatchee River (see A). Note that the time periods are different in each graph, but the magnitudes of freshwater flow events are comparable

single excursion into the lower portion of the river. Both were detected in the Glover Bight nursery hotspot, and one was detected farther upriver as far as river kilometer 7 .

In contrast, sawfish tagged in the Peace River tended to stay in or near the Harborview-Protected Cove nursery hotspot (river kilometer $\sim 10$ ) regardless of environmental conditions, including large freshwater inflow events that mirrored the magnitudes observed in the Caloosahatchee River (Figs. 6C,D \& $7 \mathrm{C}, \mathrm{D})$. This long-term residence at the nursery hotspot occurred for age 0 and age 1+ size classes. However, 6 individuals (both size classes) temporarily relocated downriver, beyond the mouth of the river, and 4 (both size classes) of the 6 relocated after high freshwater flows $\left(>100 \mathrm{~m}^{3} \mathrm{~s}^{-1}\right.$; Fig. 6D). These relocations occurred quickly (a few days) and were comparable to behaviors and distances covered by individuals in the Caloosahatchee River during the study period (see above). In addition, 4 of the 6 individuals tagged outside the Peace River near the Myakka River moved into the Peace River while they were being monitored.

The relationship between salinity and mean river position of sawfish differed between the 2 nurseries. In the Caloosahatchee River, sawfish generally moved upriver as salinity increased (to $>20$ ) and then downriver as salinity approached zero (salinity taken from reference station; Fig. 8A). In the Peace River, sawfish generally stayed within 2 to 5 river kilometers of river kilometer 10 regardless of seasonal changes in salinity (Fig. 8B). During normal conditions, the best-fit linear regressions (all sawfish pooled) of mean river position versus salinity were 

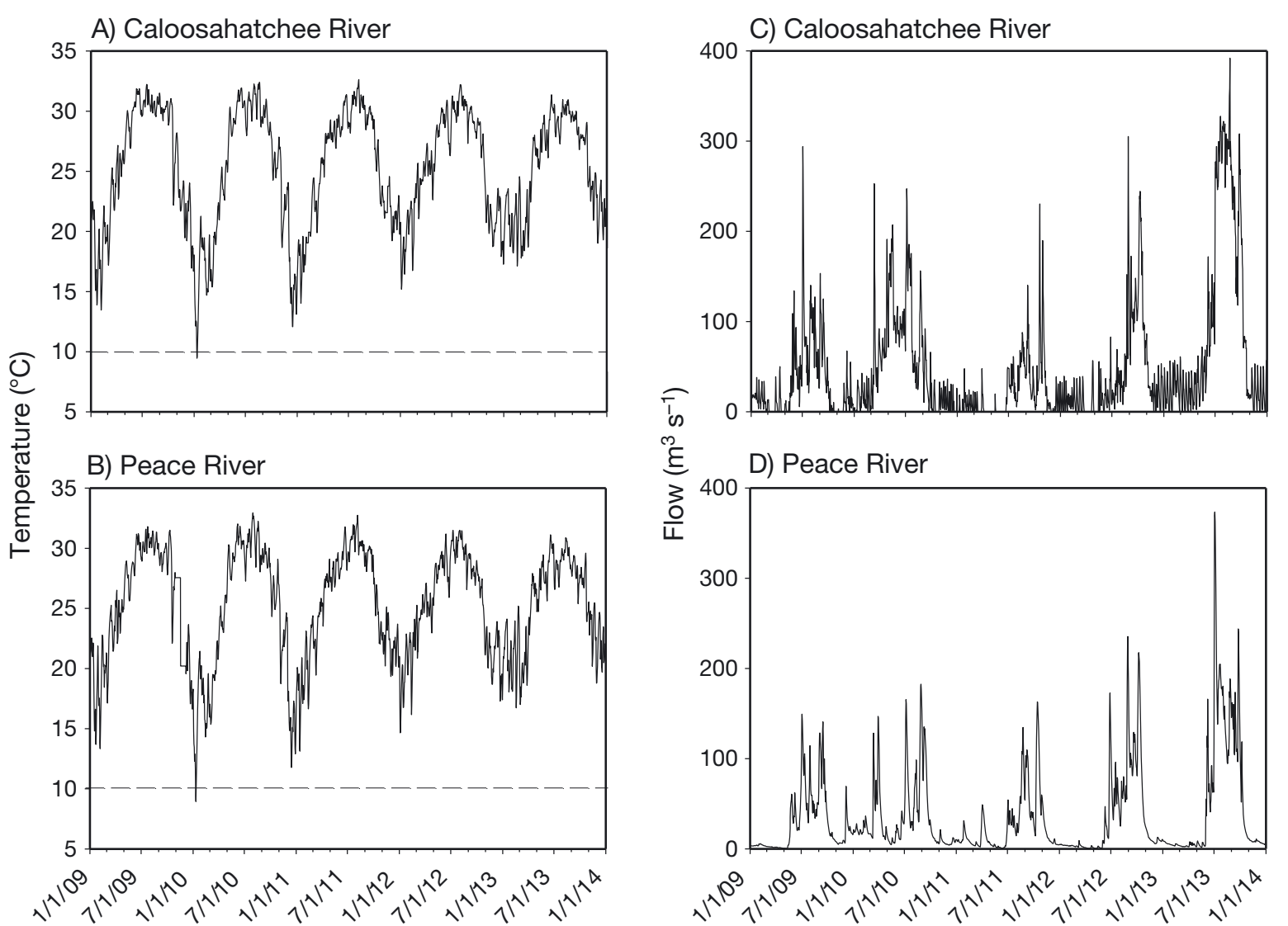

Date $(\mathrm{mo} / \mathrm{d} / \mathrm{yr})$

Fig. 7. Water temperature and freshwater inflow in the Caloosahatchee and Peace rivers between 2009 and 2013. Mean daily water temperatures were taken at permanent water management district stations at (A) river kilometer 11 in the Caloosahatchee River and (B) river kilometer 15 in the Peace River. Multiple smalltooth sawfish Pristis pectinata died during January 2010 when water temperatures dropped below $10^{\circ} \mathrm{C}$ in both rivers. Multiple sawfish congregated, but did not die, in the Glover Bight (Caloosahatchee River) nursery hotspot during December 2010 when water temperatures approached $10^{\circ} \mathrm{C}$. Mean daily freshwater flows were taken at permanent stations at (C) river kilometer 40 in the Caloosahatchee River and (D) river kilometer 15 in the Peace River. Note the differences in the curves between the flow-managed Caloosahatchee River and the natural-flow Peace River. The Caloosahatchee River curve looks more erratic and includes many dry season water releases out of Lake Okeechobee, whereas the Peace River curve is smooth and does not have many dry-season inflow peaks

greatest for $60 \mathrm{~d}$ continuously lagged salinity in the Caloosahatchee River compared to a 3 d lagged response in the Peace River (Tables 4 \& 5).

\section{Cold events}

Two unusual cold events occurred in Florida during the study period, an extreme event in January 2010 ( 1 to 15 January) and another less severe, but longer event in December 2010 ( 6 December to 2 January) (Fig. 7A,B). During the extreme event, minimum daily air temperatures reached $\sim 5^{\circ} \mathrm{C}$ (Stevens et al. 2016), and during this time, 16 sawfish (15 juveniles and 1 adult) were reported dead across Florida after water temperatures dropped below $10^{\circ} \mathrm{C}$ in both nurseries. On 16 December 2010, during the less severe event, a cluster of encounter reports from the public indicated stationary and slowly swimming sawfish in the Glover Bight nursery hotspot, which is lined by red mangroves, includes shallow and deep water, and a marina. We investigated the marina area and observed at least 12 smalltooth sawfish (up to $\sim 2.5 \mathrm{~m} \mathrm{STL}$ ) for several hours to monitor their behavior. These individuals congregated in Glover Bight, but did not die when water temperatures approached $10^{\circ} \mathrm{C}$. The larger individuals were observed in deeper water (1 to $2 \mathrm{~m}$ ) and the smaller individuals were shallower $(<1 \mathrm{~m})$ with other coldsensitive species such as common snook Centropomus undecimalis. Two of the larger smalltooth sawfish (215.6 and $218.7 \mathrm{~cm}$ STL) were tagged with acoustic transmitters, and both stayed in the Glover Bight nursery hotspot for at least 1 wk after being 


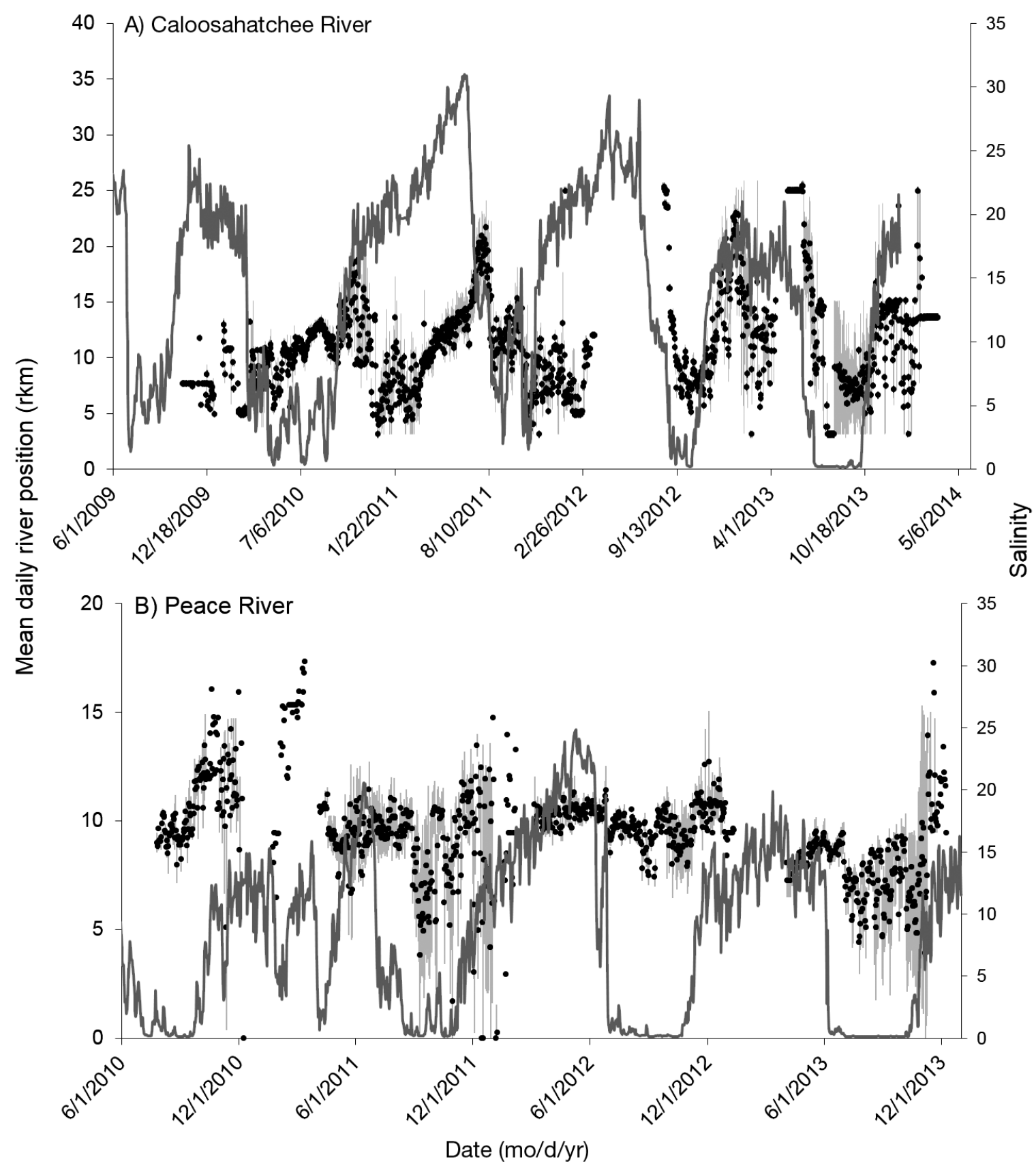

Fig. 8. Mean daily river position (mean \pm SE of all sawfish carrying acoustic transmitters on a given day) of smalltooth sawfish Pristis pectinata relative to mean daily salinity in the (A) Caloosahatchee River (June 2009 to May 2014) and (B) Peace River (June 2010 to December 2013). Gray lines: salinity; black dots: mean river position of sawfish; vertical gray lines associated with dots: SE. Three mean daily river position-estimates from sawfish that left the Peace River briefly and returned received negative values, but were adjusted to zero for this figure

tagged. The $215.6 \mathrm{~cm}$ individual left Glover Bight after $1 \mathrm{wk}$, returned to Glover Bight on 2 occasions for 2 and $8 \mathrm{~d}$ periods during the following month, and in general began moving upriver for the remainder of its 5 mo monitoring period, which is a typical movement direction during the dry season. The $218.7 \mathrm{~cm}$ sawfish remained in Glover Bight for almost 1 mo after being tagged and remained associated with this nursery hotspot for its entire 6 mo monitoring period. It appeared as if this individual was moving downriver (where there were no listening stations) and back to Glover Bight.

Smalltooth sawfish behavior was clearly affected by both cold events. Typically, during periods of in- 
Table 4. Caloosahatchee River: linear regressions of smalltooth sawfish Pristis pectinata mean river position versus continuously lagged mean salinity. The regression analysis was conducted separately for 2 time periods to account for the effects of 2 cold events, one in January 2010 and another in December 2010). Salinity is normally an important driver of habitat use in this river (Poulakis et al. 2013), but was not during and after the cold events. Best-fit regression is indicated in bold

\begin{tabular}{|cccccc|}
\hline \multirow{2}{*}{ Salinity lag (d) } & $d f$ & Intercept & Slope & $p$ & Adj $R^{2}$ \\
\hline 1 Apr 2010 to 31 Dec 2011 (cold event time period) \\
0 & 638 & 10.56 & 0.02 & 0.176 & 0.00 \\
3 & 638 & 10.50 & 0.02 & 0.107 & 0.00 \\
7 & 638 & 10.47 & 0.03 & 0.076 & 0.00 \\
14 & 638 & 10.42 & 0.03 & 0.046 & 0.00 \\
30 & 638 & 10.25 & 0.04 & 0.006 & 0.01 \\
60 & 638 & 9.92 & 0.07 & $<0.001$ & 0.02 \\
90 & 638 & 9.80 & 0.08 & $<0.001$ & 0.03 \\
120 & 638 & 9.64 & 0.09 & $<0.001$ & 0.03 \\
$\mathbf{1}$ & Apr 2012 to 31 Dec $\mathbf{2 0 1 3}$ (normal conditions) & \\
0 & 467 & 9.33 & 0.26 & $<0.001$ & 0.12 \\
3 & 467 & 9.12 & 0.29 & $<0.001$ & 0.14 \\
7 & 467 & 8.92 & 0.31 & $<0.001$ & 0.16 \\
14 & 467 & 8.59 & 0.35 & $<0.001$ & 0.20 \\
30 & 467 & 7.95 & 0.42 & $<0.001$ & 0.28 \\
$\mathbf{6 0}$ & $\mathbf{4 6 7}$ & $\mathbf{7 . 1 5}$ & $\mathbf{0 . 5 2}$ & $<\mathbf{0 . 0 0 1}$ & $\mathbf{0 . 3 5}$ \\
90 & 467 & 6.83 & 0.54 & $<0.001$ & 0.32 \\
120 & 467 & 6.94 & 0.50 & $<0.001$ & 0.24 \\
\hline
\end{tabular}

creasing salinity (dry season), the mean position of all sawfish moves upriver (Poulakis et al. 2011, 2013). But during the cold events, most sawfish in the Caloosahatchee River moved downriver when salinity was increasing (Fig. 9). During the cold event-affected time period, $\mathrm{R}^{2}$ values were low in both nurseries ( 0 to 0.04 ; Tables 4 \& 5), and there was no relationship between mean sawfish position and salinity.

\section{DISCUSSION}

\section{Spatial considerations within the nursery: the importance of nursery hotspots}

The Caloosahatchee and Peace rivers were defined as smalltooth sawfish Pristis pectinata nurseries by Poulakis et al. (2011) based on criteria defined for elasmobranchs by Heupel et al. (2007). Within these nurseries, multiple lines of evidence gathered over almost a decade have documented specific areas of high use, or nursery hotspots, for juvenile smalltooth sawfish (Simpfendorfer et al. 2010, Poulakis et al. 2011, 2013, 2016, Nagelkerken et al. 2015, Hollensead et al. 2016). The present study, which was as
Table 5. Peace River: linear regressions of smalltooth sawfish Pristis pectinata mean river position versus continuously lagged mean salinity. The regression analysis was conducted separately for 2 time periods to account for the effects of 2 cold events, one in January 2010 and another in

December 2010. Best-fit regression is indicated in bold

\begin{tabular}{|cccccc|}
\hline \multirow{2}{*}{ Salinity lag (d) } & df & Intercept & Slope & $p$ & Adj R \\
\hline \multicolumn{7}{c}{ 1 Apr 2010 to 31 Dec 2011 (cold event time period) } \\
0 & 440 & 9.37 & 0.09 & $<0.001$ & 0.036 \\
3 & 440 & 9.42 & 0.08 & $<0.001$ & 0.030 \\
7 & 440 & 9.45 & 0.08 & $<0.001$ & 0.025 \\
14 & 440 & 9.51 & 0.07 & 0.002 & 0.021 \\
30 & 440 & 9.55 & 0.07 & 0.008 & 0.014 \\
60 & 440 & 9.53 & 0.07 & 0.01 & 0.013 \\
90 & 440 & 9.65 & 0.05 & 0.109 & 0.004 \\
120 & 440 & 9.91 & 0.01 & 0.831 & 0.000 \\
$\mathbf{1}$ & Apr 2012 to $\mathbf{3 1} \mathbf{D e c} \mathbf{2 0 1 3}$ (normal conditions) \\
0 & 532 & 8.37 & 0.10 & $<0.001$ & 0.220 \\
$\mathbf{3}$ & $\mathbf{5 3 2}$ & $\mathbf{8 . 3 6}$ & $\mathbf{0 . 1 0}$ & $<\mathbf{0 . 0 0 1}$ & $\mathbf{0 . 2 2 2}$ \\
7 & 532 & 8.38 & 0.10 & $<0.001$ & 0.207 \\
14 & 532 & 8.37 & 0.10 & $<0.001$ & 0.205 \\
30 & 532 & 8.38 & 0.09 & $<0.001$ & 0.185 \\
60 & 532 & 8.47 & 0.08 & $<0.001$ & 0.121 \\
90 & 532 & 8.56 & 0.06 & $<0.001$ & 0.070 \\
120 & 532 & 8.64 & 0.05 & $<0.001$ & 0.037 \\
\hline \multicolumn{7}{c}{} & & & & & \\
\hline
\end{tabular}

comprehensive as previous work in the Caloosahatchee River nursery, included a random-sampling approach, an acoustic monitoring array, and broad sampling coverage of northern Charlotte Harbor, including the Peace River, and still concluded that juvenile sawfish occurred almost exclusively in the Harborview-Protected Cove nursery hotspot, making it the only known nursery hotspot in the northern portion of the Charlotte Harbor Estuary Unit of juvenile critical habitat. Recent genetic evidence has shown that adult female smalltooth sawfish return to the Caloosahatchee or Peace rivers every other year to give birth (Feldheim et al. 2017). Assuming survival of adults, this evidence promotes long-term use of both nurseries within the Charlotte Harbor Estuary Unit of juvenile critical habitat and likely long-term use of the well-documented nursery hotspots within them. Further, in light of research that has shown residency, site fidelity, and philopatry of smalltooth sawfish in both nurseries (e.g. Simpfendorfer et al. 2011, Poulakis et al. 2011, 2013, 2016, Feldheim et al. 2017), the remaining population is likely structured on a finer geographic scale than might be expected on the basis of their limited potential for dispersal (Chapman et al. 2015). Thus, this information should be used to focus future sampling efforts, calibrate the temporal scale of population assessments, and for long-term recovery planning. 

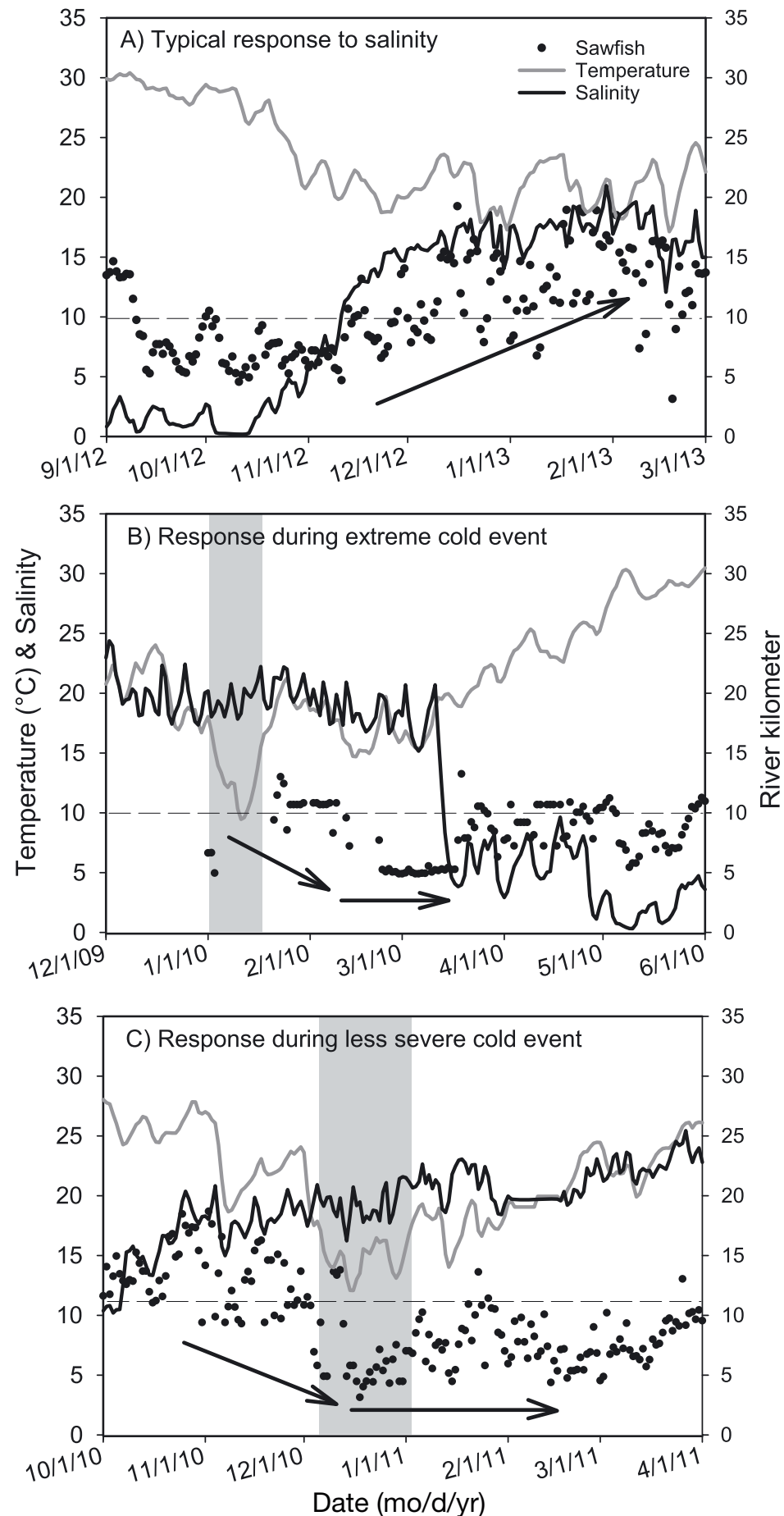

Fig. 9. Mean daily river position (mean of all smalltooth sawfish Pristis pectinata carrying acoustic transmitters on a given day) relative to mean daily salinity and temperature in the Caloosahatchee River nursery during (A) a typical response to seasonal changes in salinity, (B) the extreme cold event ( 1 to 15 January 2010; gray bar), and (C) the less severe cold event ( 6 December 2010 to 2 January 2011; gray bar). Black lines: salinity; black dots: sawfish mean river position; gray line: temperature; arrows: direction of sawfish movements. The typical sawfish response to seasonal increases in salinity is movement upriver. However, during both cold events, sawfish moved downriver during periods of increasing salinity

\section{Habitat use in both nurseries \\ Similarities and differences under normal seasonal conditions}

Smalltooth sawfish used all habitats available to them in both nurseries. Individuals from neonates to $2.2 \mathrm{~m}$ STL used mainstem and non-main-stem habitats such as red-mangrove lined creeks and seawall canals, which corroborates previous studies conducted in the Caloosahatchee River (Poulakis et al. 2013, 2016), but has never been documented before in the Peace River. Non-main-stem habitats were used more in the Caloosahatchee River, but less of these habitats are present in the Peace River (e.g. far fewer seawall canal systems; see Figs. 1-3). While only a portion of habitats were monitored in both nurseries (due to financial and logistical limitations), creeks, canals, and all types of shorelines should be considered potential habitat for all sizes of sawfish examined in this study.

The environmental variables that influenced the probability of catching a sawfish varied between the 2 nurseries. In the logistic regression models, season was an influential parameter in both nurseries. The probability of catching a sawfish was greatest in spring (Peace River) or summer (Caloosahatchee River), which is consistent with the peak in parturition reported in Poulakis et al. (2011). Although normally an important driver of habitat use (Poulakis et al. 2013), salinity was not a major influential parameter during the entire study period due to the cold events, but was an important parameter in the Peace River model. This is related to the propensity of sawfish to remain at the single nursery hotspot in the lower Peace River (discussed in detail in the 'Discussion: Effect of freshwater inflow on static and dynamic habitat use'). Dissolved oxygen was an influential variable in the Caloosahatchee River, but not in the Peace River. This difference may be related to artificially high dissolved oxygen values caused by the Caloosahatchee River's regulated flow regime (FDEP 2013). The increase in dissolved oxygen occurs when nutrients are loaded into the Caloosahatchee River during high flow periods, which 
increases plant productivity and causes supersaturation of the water and an artificially high dissolved oxygen profile (FDEP 2013). In general, water temperature was not a major influence on broad-scale habitat use, but it became a major driver of sawfish behavior during aperiodic cold events.

\section{Aperiodic cold events}

An 80 yr extreme cold event occurred during January 2010 that quickly drove water temperatures below $10^{\circ} \mathrm{C}$ and caused widespread mortality of coldsensitive fishes that live at the northern edge of their distributions, including common snook Centropomus undecimalis (Blewett \& Stevens 2014, Stevens et al. 2016), and smalltooth sawfish (Poulakis et al. 2011). Enough common snook died that the fishery was temporarily closed (FWC Executive Order 10-03) and at least 16 sawfish (15 juveniles and 1 adult) died in Florida. A less severe cold event occurred the following winter that elicited similar behavioral changes, but no known mortalities. Collectively, these cold events support our lower lethal temperature estimate of 8 to $12^{\circ} \mathrm{C}$ for this species depending on water depth and exposure time (Poulakis et al. 2011).

On the scale of the Caloosahatchee River nursery, the cold events elicited atypical movements, as evidenced by the lack of a relationship between movements and freshwater inflow effects (e.g. salinity) during 2010 and 2011. For example, we expected movement responses related to salinity to have $\mathrm{R}^{2}$ values between 0.25 and 0.62 (Poulakis et al. 2013); however, during 2010 and 2011, the $\mathrm{R}^{2}$ value was only 0.03. This was because the mean positions of sawfish moved downriver during winters 2009/2010 and 2010/2011, when previously they have moved upriver during these periods of increasing salinity (Simpfendorfer et al. 2011, Poulakis et al. 2013). These atypical movements likely occurred because sawfish were seeking less variable, warmer waters, which are found in deeper habitats closer to the Gulf of Mexico (Boucek et al. 2017). In general, these data indicate that extreme cold temperatures elicit behaviors that are independent of the typical behavioral effects of freshwater inflow variability during normal temperature regimes. While the cold events were short-lived ( 2 to $4 \mathrm{wk})$, sawfish responses to these events diverged from typical movement patterns for up to 6 mo after the events ended. Extreme climatic events can have effects on tropical species initially, followed by long-term recoveries (Stevens et al. 2016).
These responses of smalltooth sawfish to low water temperatures may be useful in reconstructing the historic range of the species, which is not well understood, and predicting where long-term range expansion would likely occur. For example, there is anecdotal documentation of adult smalltooth sawfish in the Atlantic Ocean off states north of Florida (Bigelow \& Schroeder 1953), but their sensitivity to water temperatures below $10^{\circ} \mathrm{C}$ suggests that these were strictly summer migrants. Similarly, nurseries may persist only at latitudes where water temperatures consistently remain above $10^{\circ} \mathrm{C}$ during the winter. These observations have important implications for long-term recovery planning.

\section{Effect of freshwater inflow on static and dynamic habitat use}

The position of smalltooth sawfish in the riverine nurseries and their response to freshwater inflows is important to resource managers responsible for developing targets for minimum flows and levels for the rivers (Flannery et al. 2002, Greenwood et al. 2006). Sklar \& Browder (1998) conceptualized the trade-offs animals go through between staying in specific areas of rivers and moving to new locations. Optimal static habitat would apply to specific factors such as vegetation type(s) and water depths, whereas optimal dynamic habitat usually refers to a specific salinity range. For a given species, the preferred zone is often the place where optimum static and dynamic habitats overlap. When freshwater inflow changes, individuals must either move with the dynamic habitat or remain associated with the static habitat. For the smalltooth sawfish, the nursery hotspots discussed above contain the static habitats, and salinity represents dynamic habitat.

During normal, non-cold-event years, sawfish movements in both nurseries were related to salinity $\left(\mathrm{R}^{2}=0.22-0.36\right.$ during 2012 and 2013), but the lags between changes in salinity and movement of sawfish differed between them $(60 \mathrm{~d}$ in the Caloosahatchee River vs. $3 \mathrm{~d}$ in the Peace River). Long salinity lags (up to $90 \mathrm{~d}$ ) have been reported for the Caloosahatchee River (Poulakis et al. 2013). Poulakis et al. (2013) speculated that these lags were from a high tolerance to salinity, a strong affinity for nursery hotspots, or indirect cues from prey movements. The general pattern of sawfish relocations in the Caloosahatchee River was quickly downriver (post-lag, over a few days) during abrupt high-inflow events (with a threshold of $\sim 100 \mathrm{~m}^{3} \mathrm{~s}^{-1}$ ), followed by slower upriver 
movements over a few weeks after flows subsided. Sawfish in the Caloosahatchee River made use of the 4 nursery hotspots during these relocations. However, relocations in the Peace River were nearly instantaneous and the distance of movement was small (i.e. the slope of sawfish position vs. freshwater inflow regression was shallow). Relocations occurred over the short ( $\sim 10$ river kilometers), wide, relatively high-salinity portion of the Peace River mouth, where there is only one nursery hotspot (Poulakis et al. 2011, Huston et al. 2017, this Theme Section). Even modest relocations from this hotspot ( $\sim 5$ river kilometers) result in sawfish leaving the river mouth or moving into the narrow, upriver section of the river. For example, in the Peace River, if the salinity dropped from 30 to 5, sawfish would be expected to move only 2.5 river kilometers downriver, whereas if the salinity changed similarly in the Caloosahatchee River, sawfish would be expected to move 12.9 river kilometers. Ultimately, in the context of the static versus dynamic trade-off concept of Sklar \& Browder (1998), smalltooth sawfish responded to both static and dynamic habitat factors in the Caloosahatchee River and to mostly static habitat factors in the Peace River.

\section{River management within critical habitat}

Much of the freshwater flow down the Caloosahatchee River is managed directly through the Franklin Lock, whereas natural flow down the Peace River is only influenced indirectly through water withdrawals for human consumption. These flow differences between the 2 nurseries in the Charlotte Harbor Estuary Unit can be visualized by comparing the daily mean flow in each river during the study period (Fig. $7 \mathrm{C}, \mathrm{D}$ ). The natural flows of the Peace River had a noticeably smoother curve compared to the Caloosahatchee River, which had more extended and sometimes abrupt flows from unnatural dry season releases. For example, between July and December 2013, freshwater flow was $>200 \mathrm{~m}^{3} \mathrm{~s}^{-1}$ for $71 \mathrm{~d}$ in the Caloosahatchee River; this flow magnitude was reached on only 6 days in the Peace River. Similarly, dry-season releases occurred during 4 consecutive winters (2010/2011 to 2013/2014); these out-of-phase releases coincided with short-term ( $1 \mathrm{~d}$ to $2 \mathrm{wk}$ ) downriver movements, during times when sawfish would normally be relocating upriver (see Fig. 6A,B). How these dry-season releases might affect sawfish over the long-term (e.g. slowing growth, increasing predation, increasing stress) is unknown. Such releases do not occur in the Peace River.
Inter-nursery differences in inflow patterns likely influenced smalltooth sawfish residency, site fidelity, and relocation patterns. In the context of the ecosystem, sawfish move in direct response to flows (e.g. during storm-related flow, dry-season releases) or indirectly as their prey react to the changing conditions. We hypothesize that fish prey availability is likely a major driver of smalltooth sawfish habitat use because they grow so fast during their early life history (Simpfendorfer et al. 2008b, Scharer et al. 2012, Poulakis et al. 2017); research is under way to further explore this association.

Comparing combined and individual smalltooth sawfish movement tracks between the Caloosahatchee and Peace rivers, it is apparent that sawfish within disparate nurseries are influenced by freshwater flow effects and show habitat plasticity over areas with different river geomorphology. The lower Peace River ( 10 river kilometers) is less than onethird as long as the Caloosahatchee River ( 35 river kilometers; Poulakis et al. 2011). While geomorphology differs between them, smalltooth sawfish have adapted to both river systems. Similarly, other Florida estuarine species such as common snook and bull sharks also have shown habitat plasticity over areas with geomorphological differences (e.g. Stevens et al. 2007, Matich \& Heithaus 2012). These studies highlight the need to study species in a variety of settings and on long time scales to maximize understanding of their life histories and application of these data to management needs. For smalltooth sawfish, other areas of localized maximum freshwater input throughout the range (e.g. Faka Union canal, St. Lucie River) may function as unique nurseries, and determining long-term habitat use patterns there and comparing them to what we have documented in the Charlotte Harbor Estuary Unit of juvenile critical habitat will be important from species-specific and ecosystem perspectives.

Hotspots of animal relative abundance identify the core areas of habitat mosaics (Nagelkerken et al. 2015), and for juvenile smalltooth sawfish, the presence of nursery hotspots has become increasingly well documented in multiple nurseries throughout their range (Simpfendorfer et al. 2010, Poulakis et al. 2011, 2013, 2016, Hollensead et al. 2016, Huston et al. 2017). These nursery hotspots are emerging as areas of special conservation concern, especially because of recently documented parturition site-fidelity (philopatry) to individual nurseries (Feldheim et al. 2017). While current regulations protect these areas as part of broadly designated juvenile critical habitat, research should continue to document this phenome- 
non throughout the current range and refine the boundaries of known nursery hotspots (Poulakis et al. 2016, Huston et al. 2017) to properly inform managers about specific areas that are critical for promoting long-term recovery and to designate extra protection to them if necessary (e.g. timing of dredging and construction projects).

Acknowledgements. This work is ongoing and has been supported by funding from The Nature Conservancy (grant award number 01122014-001) and the US Department of Commerce (DOC), National Oceanic and Atmospheric Administration's (NOAA) National Marine Fisheries Service through Section 6 (Cooperation with the States) of the US Endangered Species Act under the following grant award to the Florida Fish and Wildlife Conservation Commission (FWC): from the DOC, NOAA - NA10NMF4720032. Bland Crowder, Janet Ley, Courtney Saari, and 4 anonymous reviewers improved earlier versions of the manuscript. This research was conducted under Endangered Species Permit numbers 1475 and 15802 issued by NOAA Fisheries. This work was presented as part of the symposium 'Biology and Ecology of Sawfishes' at the 2016 annual meeting of the American Elasmobranch Society, which was supported by funding from the Save Our Seas Foundation, Disney Conservation Fund, and the American Elasmobranch Society.

\section{LITERATURE CITED}

Akaike $H$ (1973) Information theory and an extension of the maximum likelihood principle. In: Petrov BN, Csaki F (eds) Proc $2^{\text {nd }}$ Int Symp Information Theory. Akademiai Kiado, Budapest, p 267-281

Bakenhaster MD, Bullard SA, Curran SS, Kritsky DC and others (2018) Parasite component community of smalltooth sawfish off Florida: diversity, conservation concerns, and research applications. Endang Species Res, doi:10.3354/esr00863

Barnes T (2005) Caloosahatchee Estuary conceptual ecological model. Wetlands 25:884-897

Beck MW, Heck KL Jr, Able KW, Childers DL and others (2001) The identification, conservation, and management of estuarine and marine nurseries for fish and invertebrates. Bioscience 51:633-641

Bigelow HB, Schroeder WC (1953) Sawfishes, guitarfishes, skates, rays, and chimaeroids. In: Tee-Van J, Breder CM, Parr AE, Schroeder W, Schultz LP (eds) Fishes of the western North Atlantic, Part 2. Sears Foundation for Marine Research, Yale University, New Haven, CT

Blewett DA, Stevens PW (2014) Temperature variability in a subtropical estuary and implications for common snook Centropomus undecimalis, a cold-sensitive fish. Gulf Mex Sci 2014:44-54

Boucek RE, Heithaus MR, Santos R, Stevens PW, Rehage JS (2017) Can animal habitat use patterns influence their vulnerability to extreme climate events? An estuarine sportfish case study. Glob Change Biol 23:4045-4057

Branstetter S (1990) Early life-history implications of selected carcharinoid and lamnoid sharks of the Northwest Atlantic. In: Pratt HL, Gruber SH, Taniuchi T (eds) Elasmobranchs as living resources: advances in the biology, ecology, systematics, and the status of the fisheries.
NOAA Tech Rep NMFS 90, US Department of Commerce, Washington, DC, p 17-28

Burnham KP, Anderson DR (2002) Model selection and inference: an information-theoretic approach, $2^{\text {nd }}$ edn. Springer-Verlag, New York, NY

Carlson J, Wiley T, Smith K (2013) Pristis pectinata. The IUCN Red List of Threatened Species 2013: e.T18175 A43398238. http://dx.doi.org/10.2305/IUCN.UK.2013-1. RLTS.T18175A43398238.en (accessed 17 Apr 2017)

Chapman DD, Simpfendorfer CA, Wiley TR, Poulakis GR and others (2011) Genetic diversity despite population collapse in a critically endangered marine fish: the smalltooth sawfish (Pristis pectinata). J Hered 102:643-652

* Chapman DD, Feldheim KA, Papastamatiou YP, Hueter RE (2015) There and back again: a review of residency and return migrations in sharks, with implications for population structure and management. Annu Rev Mar Sci 7: $547-570$

Collins AB, Heupel MR, Simpfendorfer CA (2008) Spatial distribution and long-term movement patterns of cownose rays Rhinoptera bonasus within an estuarine river. Estuar Coast 31:1174-1183

Faria VV, McDavitt MT, Charvet P, Wiley TR, Simpfendorfer CA, Naylor GJP (2013) Species delineation and global population structure of Critically Endangered sawfishes (Pristidae). Zool J Linn Soc 167:136-164

* FDEP (Florida Department of Environmental Protection) (2013) Technical support document: derivation of dissolved oxygen criteria to protect aquatic life in Florida's fresh and marine waters. Florida Department of Environmental Protection, Tallahassee, FL. www.dep.state.fl.us/ water/tmdl/docs/tsd-do-criteria-aquatic-life.pdf

Feldheim KA, Fields AT, Chapman DD, Scharer RM, Poulakis GR (2017) Insights into reproduction and behavior of the smalltooth sawfish Pristis pectinata. Endang Species Res 34:463-471

Fernald EA, Purdum ED (eds) (1998) Water resources atlas of Florida. Institute of Science and Public Affairs, Florida State University, Tallahassee, FL

*Flannery MS, Peebles EB, Montgomery RT (2002) A percent of flow approach for managing reductions of freshwater inflows from unimpounded rivers to southwest Florida estuaries. Estuaries 25:1318-1332

Frisk MG, Miller T, Dulvy NK (2005) Life histories and vulnerability to exploitation of elasmobranchs: inferences from elasticity, perturbation and phylogenetic analyses. J Northwest Atl Fish Sci 35:27-45

Greenwood MFD, Stevens PE, Matheson RE Jr (2006) Effects of the 2004 hurricanes on the fish assemblages in two proximate southwest Florida estuaries: change in the context of multi-annual variability. Estuar Coast 29:985-996

*Heupel MR, Hueter RE (2002) Importance of prey density in relation to the movement patterns of juvenile blacktip sharks (Carcharhinus limbatus) within a coastal nursery area. Mar Freshw Res 53:543-550

*Heupel MR, Simpfendorfer CA (2008) Movement and distribution of young bull sharks Carchahinhus leucas in a variable estuarine environment. Aquat Biol 1:277-289

*Heupel MR, Carlson JK, Simpfendorfer CA (2007) Shark nursery areas: concepts, definition, characterization and assumptions. Mar Ecol Prog Ser 337:287-297

Hollensead LD, Grubbs RD, Carlson JK, Bethea DM (2016) Analysis of fine-scale daily movement patterns of juvenile Pristis pectinata within a nursery habitat. Aquat Conserv 26:492-505 
Hosmer DW, Lemeshow S (2000) Applied logistic regression. John Wiley \& Sons, New York, NY

Hurvich CM, Tsai C (1989) Regression and time series model selection in small samples. Biometrika 76:297-307

*Huston CA, Stevens PW, Blaxton RM, Tolley SG, Scharer RM, Tornwall BM, Poulakis GR (2017) Diel movements of juvenile smalltooth sawfish: implications for defining the size of a nursery hotspot. Endang Species Res 34:311-322

Kyne PM, Carlson J, Smith K (2013) Pristis pristis. The IUCN Red List of Threatened Species 2013: e.T18584848 A18620395. http://dx.doi.org/10.2305/IUCN.UK.2013-1. RLTS.T18584848A18620395.en (accessed 17 Apr 2017)

Matich P, Heithaus MR (2012) Effects of an extreme temperature event on the behavior and age structure of an estuarine top predator, Carcharhinus leucas. Mar Ecol Prog Ser 447:165-178

* Matich P, Heithaus MR (2014) Multi-tissue stable isotope analysis and acoustic telemetry reveal seasonal variability in the trophic interactions of juvenile bull sharks in a coastal estuary. J Anim Ecol 83:199-213

Nagelkerken I, Sheaves M, Baker R, Connolly RM (2015) The seascape nursery: a novel spatial approach to identify and manage nurseries for coastal marine fauna. Fish Fish 16:362-371

NMFS (United States National Marine Fisheries Service) (2009) Endangered and threatened species; critical habitat for the endangered distinct population segment of smalltooth sawfish. Fed Regist 74:45353-45378

Norton SL, Wiley TR, Carlson JK, Frick AL, Poulakis GR, Simpfendorfer CA (2012) Designating critical habitat for juvenile endangered smalltooth sawfish in the United States. Mar Coast Fish 4:473-480

Poulakis GR, Stevens PW, Timmers AA, Wiley TR, Simpfendorfer CA (2011) Abiotic affinities and spatiotemporal distribution of the endangered smalltooth sawfish, Pristis pectinata, in a south-western Florida nursery. Mar Freshw Res 62:1165-1177

Poulakis GR, Stevens PW, Timmers AA, Stafford CJ, Simpfendorfer CA (2013) Movements of juvenile endangered smalltooth sawfish, Pristis pectinata, in an estuarine river system: use of non-main-stem river habitats and lagged responses to freshwater inflow-related changes. Environ Biol Fishes 96:763-778

Poulakis GR, Stevens PW, Timmers AA, Stafford CJ and others (2016) Long-term site fidelity of endangered smalltooth sawfish (Pristis pectinata) from different mothers. Fish Bull 114:461-475

Poulakis GR, Urakawa H, Stevens PW, DeAngelo JA and others (2017) Sympatric elasmobranchs and fecal samples provide insight into the trophic ecology of the smalltooth sawfish. Endang Species Res 32:491-506

R Core Team (2016) R: a language and environment for statistical computing. R Foundation for Statistical Com-

Editorial responsibility: Dean Grubbs (Guest Editor), St. Teresa, Florida, USA puting, Vienna

Royall RM (1997) Statistical evidence: a likelihood paradigm. Chapman \& Hall, New York, NY

* Scharer RM, Patterson WF III, Carlson JK, Poulakis GR (2012) Age and growth of endangered smalltooth sawfish (Pristis pectinata) verified with LA-ICP-MS analysis of vertebrae. PLOS ONE 7:e47850

Seitz JC, Poulakis GR (2002) Recent occurrence of sawfishes (Elasmobranchiomorphi: Pristidae) along the southwest coast of Florida (USA). Fla Sci 65:256-266

Simpfendorfer C (2013) Pristis zijsron. The IUCN Red List of Threatened Species 2013: e.T39393A18620401. http:// dx.doi.org/10.2305/IUCN.UK.2013-1.RLTS.T39393A 18620401.en_(accessed 17 Apr 2017)

* Simpfendorfer CA, Milward NE (1993) Utilization of a tropical bay as a nursery area by sharks of the families Carcharhinidae and Sphyrnidae. Environ Biol Fishes 37: 337-345

* Simpfendorfer CA, Heupel MR, Hueter RE (2002) Estimation of short-term centers of activity from an array of omnidirectional hydrophones, and its use in studying animal movements. Can J Fish Aquat Sci 59:23-32

Simpfendorfer CA, Heupel MR, Collins AB (2008a) Variation in the performance of acoustic receivers and its implication for positioning algorithms in a riverine setting. Can J Fish Aquat Sci 65:482-492

* Simpfendorfer CA, Poulakis GR, O'Donnell PM, Wiley TR (2008b) Growth rates of juvenile smalltooth sawfish Pristis pectinata Latham in the western Atlantic. J Fish Biol 72:711-723

Simpfendorfer CA, Wiley TR, Yeiser BV (2010) Improving conservation planning for an endangered sawfish using data from acoustic telemetry. Biol Conserv 143:1460-1469

Simpfendorfer CA, Wiley TR, Yeiser BV, Poulakis GR, Stevens PW, Heupel MR (2011) Environmental influences on the spatial ecology of juvenile smalltooth sawfish (Pristis pectinata): results from acoustic monitoring. PLOS ONE 6:e16918

Sing T, Sander O, Beerenwinkel N, Lengauer T (2005) ROCR: visualizing classifier performance in R. Bioinformatics 21:3940-3941

* Sklar FH, Browder JA (1998) Coastal environmental impacts brought about by alterations to freshwater flow in the Gulf of Mexico. Environ Manage 22:547-562

Stevens PW, Blewett DA, Poulakis GR (2007) Variable habitat use by juvenile common snook, Centropomus undecimalis (Pisces: Centropomidae): applying a life-history model in a southwest Florida estuary. Bull Mar Sci 80: 93-108

* Stevens PW, Blewett DA, Boucek RE, Rehage JS and others (2016) Resilience of a tropical sport fish population to a severe cold event across five estuaries in southern Florida. Ecosphere 7:e01400

Submitted: November 2, 2016; Accepted: October 20, 2017 Proofs received from author(s): December 20, 2017 